\title{
Critical Review of Exposure and Effects: Implications for Setting Regulatory Health Criteria for Ingested Copper
}

\author{
Alicia A. Taylor ${ }^{1}$ - Joyce S. Tsuji ${ }^{2}$ - Michael R. Garry ${ }^{2}$ Margaret E. McArdle ${ }^{3} \cdot$ William L. Goodfellow Jr. ${ }^{4}$. \\ William J. Adams ${ }^{5}$. Charles A. Menzie ${ }^{4}$
}

Received: 29 May 2019 / Accepted: 23 November 2019 / Published online: 12 December 2019

(c) The Author(s) 2019, corrected publication 2022

\begin{abstract}
Decades of study indicate that copper oral exposures are typically not a human health concern. Ingesting high levels of soluble copper salts can cause acute gastrointestinal symptoms and, in uncommon cases, liver toxicity in susceptible individuals with repeated exposure. This focused toxicological review evaluated the current literature since the last comprehensive reviews (2007-2010). Our review identified limitations in the existing United States and international guidance for determining an oral reference dose (RfD) for essential metals like copper. Instead, an alternative method using categorical regression analysis to develop an optimal dose that considers deficiency, toxicity, and integrates information from human and animal studies was reviewed for interpreting an oral RfD for copper. We also considered subchronic or chronic toxicity from genetic susceptibility to copper dysregulation leading to rare occurrences of liver and other organ toxicity with elevated copper exposure. Based on this approach, an oral RfD of $0.04 \mathrm{mg} \mathrm{Cu} / \mathrm{kg} / \mathrm{day}$ would be protective of acute or chronic toxicity in adults and children. This RfD is also protective for possible genetic susceptibility to elevated copper exposure and allows for background dietary exposures. This dose is not intended to be protective of patients with rare genetic disorders for copper sensitivity within typical nutritional intake ranges, nor is it protective for those with excessive supplement intake. Less soluble mineral forms of copper in soil have reduced bioavailability as compared with more soluble copper in water and diet, which should be considered in using this RfD for risk assessments of copper.
\end{abstract}

Keywords Copper $\cdot$ Regulation $\cdot$ Toxicity Recommended dietary intake $\cdot$ Risk assessment $\cdot$ Essentiality

\section{Abbreviations}

AD Alzheimer's disease

AROI acceptable range of oral intake

Supplementary information The online version of this article (https:// doi.org/10.1007/s00267-019-01234-y) contains supplementary material, which is available to authorized users.

William L. Goodfellow

wgoodfellow@exponent.com

1 Exponent, Inc., 475 14th Street, Suite 400, Oakland, CA 94612, USA

2 Exponent, Inc., 15375 SE 30th Place, Suite 250, Bellevue, WA 98027, USA

3 Exponent, Inc., One Mill and Main Place, Suite 150, Maynard, MA 01754, USA

4 Exponent, Inc., 1800 Diagonal Road, Suite 500, Alexandria, VA 22314, USA

5 Red Cap Consulting, 7760 North Boulder Drive, Lake Point, UT 84074, USA
ASD autism spectrum disorder

ATSDR Agency for Toxic Substances and Disease Registry

BW body weight

ECHA European Chemical Agency

ECI European Copper Institute

EPA US Environmental Protection Agency

EU European Union

GLP Good laboratory practices

ICC Indian childhood cirrhosis

IOM Institute of Medicine

IRIS Integrated Risk Information System

IUD intrauterine devices

LOAEL lowest-observed-adverse-effect level

MAC maximum acceptable concentration

MCLG maximum contaminant level goal

NOAEL no-observed-adverse-effect level

NTP National Toxicology Program

NRC National Research Council

OECD Organization for Economic Co-operation and Development 
OEHHA California Office of Environmental Health Hazard Assessment

PHG public health goal

REACH European Regulation on Registration, Evaluation, Authorization, and Restriction of Chemicals

RfD reference dose

TCEQ Texas Commission on Environmental Quality

TDI tolerable daily intake

UF uncertainty factor

UDS unscheduled DNA synthesis

WHO World Health Organization.

\section{Introduction}

While copper is an essential nutrient for humans, animals, and plants, it can pose risks to human health with elevated exposure. In addition to diet and supplements, a prevalent source of copper exposure in the US is through leaching of copper from plumbing into tap water. As of 2016, $78 \%$ of newly installed utility lines used copper (CDA 2016), and it is estimated that $35-40 \%$ of single-family homes newly constructed in 2019 will have copper piping (Personal communication with CDA). Copper exposure through drinking water has been regulated in the United States since 1991 (56 FR 26460-26564), when the US Environmental Protection Agency (EPA) set a maximum contaminant level goal (MCLG) and drinking water action level for copper at $1.3 \mathrm{mg} \mathrm{Cu} / \mathrm{L}$. EPA based the MCLG on acute gastrointestinal effects observed in nurses who consumed cocktails contaminated with copper (Wyllie 1957) (estimated minimal dose of $2.65 \mathrm{mg} \mathrm{Cu} / \mathrm{L}$, divided by an uncertainty factor of 2) (Donohue 1997). Although a broader review of the scientific basis for this drinking water level was conducted for EPA in 2000 (NRC 2000), which concurred with this level at the time, EPA has not since reevaluated the MCLG or formally developed an oral reference dose (RfD) to support risk assessments of environmental copper exposure. An update of the literature and an assessment of an RfD would thus be timely.

Copper has been reviewed by numerous health authorities. EPA's Integrated Risk Information System (IRIS) evaluated copper in 1987; however, neither an oral RfD nor an inhalation reference concentration were derived (IRIS 2017), likely due to the lack of information at the time (US EPA 1988a). In 2000, EPA commissioned the National Research Council (NRC) to review the $1.3 \mathrm{mg} \mathrm{Cu} / \mathrm{L}$ EPA drinking water action level in light of more recent experimental data on acute gastrointestinal effects in humans at that time (NRC 2000). A controlled human study reported gastrointestinal symptoms at copper levels in drinking water of $\sim 3 \mathrm{mg} \mathrm{Cu} / \mathrm{L}$ with no effects at $2 \mathrm{mg} \mathrm{Cu} / \mathrm{L}$ (Pizarro et al.
1999), which was supported by unpublished data from another study sponsored by the International Copper Association. Nevertheless, NRC (2000) did not recommend increasing the MCLG because of concern for susceptible individuals with copper homeostasis disorders. The NRC reviewed both food and water ingestion studies and concluded that $1.3 \mathrm{mg} \mathrm{Cu} / \mathrm{L}$ was protective for both gastrointestinal effects of acute exposures to elevated copper in water as well as for the rare occurrences of liver toxicosis in genetically susceptible infants or children consuming milk with elevated copper levels (NRC 2000). Subsequently, the European Chemicals Agency reviewed and endorsed a voluntary risk assessment written by the European Copper Institute (ECI) on copper and copper compounds that determined that environmentally relevant concentrations of copper were of no concern (ECI 2008).

In absence of an oral RfD, EPA and some states (e.g., New Jersey) have converted the $1.3 \mathrm{mg} \mathrm{Cu} / \mathrm{L}$ EPA action level for drinking water to an RfD of $0.04 \mathrm{mg} \mathrm{Cu} / \mathrm{kg} / \mathrm{day}$ assuming $2 \mathrm{~L} / \mathrm{day}$ of water consumption and a $70 \mathrm{-kg}$ body weight (US EPA 2017). Other state, national, and international health authorities have also developed various allowable doses for copper risk assessment, allowable dietary intake, or limits for copper in drinking water. The World Health Organization (WHO) reported that 104 countries have a regulation or guideline for copper in drinking water, with a median value of $1.5 \mathrm{mg} / \mathrm{L}$ and a range of $0.05-3 \mathrm{mg} / \mathrm{L}$ (WHO 2018).

For essential mineral elements such as copper, WHO recognized the complexity of assessing limits for copper intake and defined an acceptable range of oral intake as the trough in a U-shaped curve that balances deficiency of low exposure with toxicity from excess exposure (WHO 2002). Although an oral RfD is not intended to provide essential intakes for good health, an RfD in the range of deficiency is lower than necessary for protection against toxicity from excess. Derivation of an oral RfD for copper thus needs to consider toxicity data in animals, human experimental studies, and epidemiological studies, along with the mechanistic effects of copper as an essential element in biological functions, tolerance over a wide range of doses from internal regulation of copper levels, and toxicity that results from excess internal copper, especially for some uncommon genetically susceptible groups.

Though increasing copper exposure in the US population is not a concern, a better understanding of the levels of essentiality and toxicity is needed to support the scientific basis of health-protective regulations for this element. The objectives of this review are to summarize the current knowledge on copper toxicity, assess dose-response endpoints, and provide useful information for health professionals, regulatory agencies, and policy makers for assessing the health risks of copper and determining 
whether current research warrants reevaluation of copper criteria for risk assessment and risk management of environmental exposures.

\section{Methods}

\section{Literature Search, Review, and Evaluation Methods}

The most recent authoritative reviews on copper conducted by WHO (2004) and ECI (2008) were initially evaluated with a critical review of the key studies identified by these reports. A literature review was also conducted to identify copper toxicity studies published from 2007 to 2019 using the National Library of Medicine database, PubMed, the Developmental and Reproductive Toxicology Database, ${ }^{1}$ Hazardous Substances Data Bank, International Toxicity Estimates for Risk, and Google Scholar. Broad search terms relating to various forms of copper and, health endpoints, and relevant dose/exposure information were used. Google scholar was also used with broad search terms relating to copper and health, to find additional publications. Over 260 publications were identified using all of the search engines and were reviewed for relevance.

\section{Dose-Response Assessment Methods}

Key studies selected in the above screening process were reviewed for data quality and potential relevance for developing a robust oral RfD for copper. Papers were selected on oral toxicity endpoints traditionally used for the analysis in EPA's IRIS process (IRIS 2017), including in two-generation laboratory animal studies, double-blind studies, and those with appropriate controls. Previous studies have evaluated best methods for determining an optimal copper intake (Chambers et al. 2010) and identify study designs needed to best model copper toxicity (Krewski et al. 2010a, 2010b). Specifically, an alternative nonlinear relationship used for essential nutrient toxicity that simultaneously models both deficiency and excess toxicity doseresponse curves, called categorical regression, was reviewed as a potential method for defining optimal copper intake levels (Chambers et al. 2010; Krewski et al. 2010a, 2010b; Milton et al. 2017a). More details on the categorical regression methodology are presented in limitations of deriving an EPA RfD section. Consistency with the broader literature on the mode of action of copper essentiality and toxicity and derivations of limits for copper

\footnotetext{
${ }^{1}$ DART is a database provided online by TOXNET, a toxicology data network that is sponsored by the NIH US National Library of Medicine. DART can be accessed at: https://toxnet.nlm.nih.gov/newtoxnet/ dart.htm.
}

intake or drinking water concentrations were also considered in assessing an appropriate oral RfD.

\section{Chemical Substances, Properties, and Uses}

A description of copper substances, properties, and uses is provided in section 1.0 of the Supplementary Information and in Supplementary Table S1. When possible, the form of copper is provided that was used in the publications summarized herein.

\section{Essentiality and Homeostasis}

Copper is an essential trace element necessary for all biological organisms and its levels are controlled in the body. The dysregulation of copper through impaired absorption or excretion results in deficiency or toxicity, as illustrated by two rare genetically based diseases.

\section{Role of Copper Essentiality and Normal Regulation}

In animals and plants, copper is found in many enzymes and has two main functions (ATSDR 2004; ECI 2008): (1) in fundamental reduction-oxidation reactions involving $\mathrm{Cu}$ (II) and $\mathrm{Cu}(\mathrm{I})$, such as in superoxide dismutase, hemocyanin, and cytochrome c oxidase, and (2) as a component in structural and functional proteins because of its electron transfer capabilities, with examples including neurotransmitter function, iron metabolism, and connective tissue biosynthesis (IPCS 1998). Copper-containing enzymes in humans, including but not limited to metallothionein, tyrosinase, hemocyanin, ceruloplasmin, and amine oxidase, are important in multiple systems, such as the respiratory, immune, and nervous systems. Cytochrome c oxidase, for example, is essential for brain function and energy generation in the brain (Llanos and Mercer 2002).

As summarized by Llanos and Mercer (2002), most copper homeostasis mechanisms are controlled by $\mathrm{Cu}$ ATPases, which allow cells to efflux excess copper as cupro-proteins. For example, the Cu-ATPase ATP7A is a transporter necessary for copper uptake across the small intestine and across the blood-brain barrier. Specifically, ATP7A functions as a cellular copper efflux protein, whereas ATP7B is responsible for copper biliary excretion or transport from the liver to ceruloplasmin. Other proteins are involved along with a nonspecific metal-ion transporter, DCT1, which is thought to play a minor role in dietary copper absorption.

Copper essentiality is demonstrated by its role in many physiological processes, such as fetal and infant development and growth, brain development, and function, bone 
strength, iron, glucose, and cholesterol metabolism, pigment formation, and immune function (ECI 2008). Copper requirements are met through ingestion of copper in water and foods. Average concentrations of copper found in the US tap water are between 0.02 and $0.075 \mathrm{mg} / \mathrm{L}$ (ATSDR 2004). Gaetke et al. (2014) estimated that drinking water contributes $\sim 6-13 \%$ of the average daily copper intake in the US Food sources of dietary copper include organ meats, nuts, seafood, seeds, beans, and whole grains (ATSDR 2004; WHO 2004). Median intake of copper from food sources is $0.93-1.3 \mathrm{mg} / \mathrm{day}$ for adults in the United States (ATSDR 2004). The US Institute of Medicine (IOM) also provides dietary intake values: the mean dietary intake from food alone is estimated at $1.0-1.7 \mathrm{mg} \mathrm{Cu} / \mathrm{day}$, whereas the mean dietary plus supplemental copper intake is $1.3-2.2 \mathrm{mg}$ $\mathrm{Cu} /$ day (IOM 2001). Up to $15 \%$ of US adults consumed dietary supplements containing an average of $1.3-2.2 \mathrm{mg}$ $\mathrm{Cu}$ /day as of 1986 (IOM 2001). Using average intake values of copper from water, food, and supplements, the average adult may consume an approximate total of $1.85 \mathrm{mg} \mathrm{Cu} /$ day, or equivalent to $0.026 \mathrm{mg} \mathrm{Cu} / \mathrm{kg} /$ day. ${ }^{2}$ Dietary reference values for copper have been recommended (IOM 2004), although the exact amounts of copper associated with adequate nutrition, deficiency, and toxicity have yet to be defined (Bost et al. 2016).

The essentiality of metals complicates the assessment of a RfD for health protection because of toxicity versus recommended dietary allowances for adequate nutritional requirements (US EPA 2007). Nutritional requirements vary across the population. Differences in homeostatic copper regulation also affect individual nutritional requirements and toxicity levels. Studies in monkeys and rats suggest that neonates are more sensitive to toxicity from copper exposure because of less competent regulatory capabilities that further develop with age (Fuentealba et al. 2000; Araya et al. 2005; Bauerly et al. 2005), although the tendency to accumulate more copper is offset by increased requirements in this early rapid growth period. Rare homeostatic disorders like Menke's and Wilson's diseases are examples of hereditary diseases that alter essentiality and deficiency/ toxicity levels in humans.

\section{Menke's and Wilson's Diseases}

Failure to maintain copper homeostasis within the body leads to copper deficiency or excess, both of which result in

\footnotetext{
2 This value was approximated by using intake values for adults. A 2$\mathrm{L} /$ day water intake and an average value of $0.055 \mathrm{mg} \mathrm{Cu} / \mathrm{L}$ in tap water $(0.055 \mathrm{mg} \mathrm{Cu} / \mathrm{L}$ is the average a range of $\mathrm{Cu}$ found in tap water, $0.02-0.075 \mathrm{mg} \mathrm{Cu}$ [ATSDR 2004]. $0.055 \mathrm{mg} \mathrm{Cu} / \mathrm{L}$ is multiplied by an ingestion of $1.75 \mathrm{mg} \mathrm{Cu} /$ day for food plus supplement (average between 1.3-2.2 mg Cu/day [IOM 2001]), divided by a 70-kg body weight.
}

toxicity. Two hereditary diseases in humans, Menke's disease, which is a deficiency disorder, and Wilson's disease, an excess disorder, demonstrate the consequence of copper dysregulation in humans (Danks 1995; ECI 2008). Both diseases result from genetic defects in copper transport genes for $\mathrm{Cu}$-ATPases (Llanos and Mercer 2002).

Menke's disease is an X-linked copper deficiency syndrome that occurs in 1 out of 250,000 live births (Llanos and Mercer 2002; Tønnesen et al. 1991). Impaired copper delivery out of intestinal cells by the regulatory protein $\mathrm{Cu}$ ATP7A in patients causes systemic copper deficiency characterized by hypopigmented hair and connective tissue abnormalities leading to aneurisms, loose skin, and fragile bones (Llanos and Mercer 2002). Defective transport by ATP7A also results in impaired copper distribution throughout the body, including the lack of normal transport across the blood-brain barrier resulting in neurologic deficiencies (Llanos and Mercer 2002). Inadequate copper transport also results in excess copper in the kidneys, consistent with deficient copper efflux from cells as the overall defect of this disease. Menke's disease presents in patients at $2-3$ months and is usually fatal by 3 years (de Bie et al. 2007).

Wilson's disease is an autosomal recessive disorder of copper transport in 1 out of 50,000-100,000 live births (Llanos and Mercer 2002; Danks 1995). A nonfunctional ATPase, ATP7B, results in high copper concentrations in the liver due to an inability to excrete biliary copper, causing oxidative damage, hepatocyte death, and liver failure (Llanos and Mercer 2002). Damaged hepatocytes release copper into circulation, which can accumulate in the central nervous system leading to neurotoxicity (ataxia, dementia, anxiety, and disorientation; Llanos and Mercer 2002). No overt symptoms are apparent during the gradual accumulation of copper within the body, which is then followed by a sudden onset of toxicity as hepatocytes can no longer store or complex the excess copper which accumulates in the tissues (Llanos and Mercer 2002). Onset of Wilson's disease can occur between the ages of 8-9 and early 50s, though most commonly patients are diagnosed with liver dysfunction as a teenager (DiDonato and Sarkar 1997; Goode 1991). There is a broad spectrum of clinical symptoms associated with Wilson's disease, and therefore making diagnosis a challenge (Beinhardt et al. 2014). Wilson's disease patients often need liver transplants due to liver cirrhosis (Beinhardt et al. 2014). Even patients receiving adequate treatment will have a reduced life expectancy compared with healthy individuals (Beinhardt et al. 2014). Copper has been linked to neurological effects in Wilson's disease patients, although Gromadzka et al. (2010) did not find clear evidence of increased neurological effects in the 68 heterozygotes for Wilson's disease tested when compared with 31 control subjects. 
These two diseases illustrate the consequences of the adverse effects of deficient or excess copper in the body in genetically susceptible populations; however, these conditions are not informative of the oral doses for prevention of toxicity or deficiency. Those with Wilson's disease would have toxic accumulation of copper with even the low levels of exposure necessary for good nutrition in the general population, and are a rare subpopulation that would be under medical care. The heterozygous carriers of the Wilson's disease gene are more common in the population and have been postulated to potentially have genetic susceptibility to expressing some Wilson's disease symptoms with elevated copper exposures (Brewer 2000). Genetic susceptibility has also been indicated in idiopathic liver toxicosis cases in India (NRC 2000; Nayak and Chitale 2013; Uauy et al. 2008; Sriramachari and Nayak 2008; O'Neill and Tanner 1989) and the Tyrolean region of Austria (NRC 2000; Müller et al. 1996; Uauy et al. 2008), as discussed in the section relating to liver toxicosis. Intake of copper by individuals with Wilson's (homozygous) and Menke's diseases is likely managed by their medical professionals because of the overt symptoms of these diseases, even at low copper exposure in the case of Wilson's disease. Thus, those with these diseases have not been considered for setting regulatory levels (NRC 2000).

\section{Toxicokinetics}

\section{Absorption and Elimination}

In mammals, copper absorption occurs in the upper gastrointestinal tract through active and passive transport mechanisms (WHO 2004). Copper absorption primarily occurs in the small intestine and is susceptible to competitive inhibition from transition metals such as iron or zinc (Llanos and Mercer 2002; WHO 2004). In fact, zinc is used to treat Wilson's disease via copper absorption inhibition (IOM 2001). Numerous studies have investigated copper absorption in animals and humans following oral exposures.

Absorption of copper through active transport primarily involves the copper transporter 1 (Ctr1) that is specific for transporting the monovalent $(\mathrm{Cu}(\mathrm{I}))$ form of copper into cells (including gastrointestinal cells). Copper in food can be either $\mathrm{Cu}(\mathrm{I})$ or divalent $(\mathrm{Cu}(\mathrm{II}))$ forms as $\mathrm{Cu}(\mathrm{I})$ acetate, $\mathrm{Cu}$ (II) acetate, $\mathrm{Cu}$ (I)-glutathione, $\mathrm{Cu}$ (I)-cysteine, and $\mathrm{Cu}$ (II)-histidine; whereas, copper in water is as $\mathrm{Cu}$ (II) (Ceko et al. 2014). Ctr1 is critical for development since its deletion is associated with lethality in animals (Lee et al. 2001). Active mechanisms for copper absorption from small intestine, particularly in the duodenum, involve transport through Ctr1 into the enterocytes of the duodenum. Ingested $\mathrm{Cu}$ (II) is readily reduced to $\mathrm{Cu}(\mathrm{I})$ by metalloreductase activity at the apical membrane of the gastrointestinal enterocytes (Ohgami et al. 2006; Ellingsen et al. 2015). Changes in absorption rate depending on the cellular copper status are likely related to the activity/efficiency of this enzyme and transporters like Ctr1. Higher copper exposure results in internalization of Ctr1 within the enterocytes, thereby reducing transport (Lonnerdal 2008; Van den Berghe and Klomp 2009). Ctr1 on the basement membrane side of the enterocyte can also transport copper into the enterocyte from the blood. Normal shedding of enterocytes (4-day average lifespan) into the gastrointestinal tract results in another source of elimination for the regulation of copper. Copper delivered to portal circulation is bound to histidine or serum proteins such as $\alpha 2$-macroglobulin and albumin (Van den Berghe and Klomp 2009).

Absorption in the gastrointestinal tract may also occur by diffusion through tight junctions (paracellular), although passive absorption in this manner would be less efficient than facilitated transport. Unlike calcium and magnesium absorption, little evidence supports passive paracellular uptake of copper as an important pathway for absorption under normal conditions, consistent with the lack of intestinal absorption of copper in Menke's disease and rats lacking Ctrl (Van den Berghe and Klomp 2009). On the other hand, Van den Berghe and Klomp (2009) acknowledge that paracellular transport cannot be ruled out under conditions of "superphysiological" copper intake, and that some evidence indicates preadolescent rats rely on paracellular uptake of copper, although they also show regulation of blood copper levels through accumulation in intestinal cells. Clearly, additional research is needed on the conditions in which paracellular transport of copper (including $\mathrm{Cu}(\mathrm{II})$ ) might be important.

The amount of copper absorbed by Ctr1 or by passive absorption may thus depend on the dose, whether one is copper deficient or sufficient, and gastrointestinal transit time. For example, administration of radiolabeled $\mathrm{Cu}(\mathrm{II})$ $\left(0.5 \mathrm{mCi}{ }^{64}\right.$ copper acetate; dose in $\mu \mathrm{g}$ not given but appears to be $61.7 \mu \mathrm{g}^{3}$ or $0.26 \mathrm{mg} / \mathrm{L}$ if administered in $8 \mathrm{oz}$ of fluid) in cow's milk to fasting adults resulted in peak uptake into blood of $6 \%$ of the administered dose within $1-2 \mathrm{~h}$ of ingestion (Hill et al. 1986). The rapid appearance of copper in blood is likely related to the administration of copper in a soluble form under fasting conditions. Some of the absorption may have occur through reduction of $\mathrm{Cu}$ (II) to $\mathrm{Cu}(\mathrm{I})$ and the $\mathrm{Ctr} 1$ transporter in the duodenum, although rapid gastrointestinal transit time under these conditions would have reduced the time for such transport. Although total copper absorption was not reported, a low peak absorption within $1-2 \mathrm{~h}$ suggests an overall low absorption percentage and little evidence of high exposure from passive absorption in the lower gastrointestinal tract.

\footnotetext{
Based on conversion in Van den Berg et al. (1994).
} 
Van den Berg et al. (1994) showed using radiolabeld ${ }^{64} \mathrm{Cu}$, that oral ingestion of $5 \mu \mathrm{g}$ of $\mathrm{Cu}$ administered in feed by fasting Wistar rats compared with $5 \mu \mathrm{g}$ delivered by intraperitoneal administration of a solution resulted in total absorption values of $52-56 \%$. When the same conditions were tested with a copper deficient diet $(1 \mathrm{mg} / \mathrm{kg}$ of $\mathrm{Cu}$ in feed), 58-76\% absorption occurred. In another study, where male Long Evans rats were orally administered adequate copper or copper deficient diets, absorption rates were shown as $32-39 \%$ for both diets, though absorption values may not reflect complete excretion (Johnson 1988). Other absorption research indicates that rats adjust to deficient or low copper doses by increasing copper absorption efficiency and reducing biliary excretion; rats on increased copper diets show a decreased absorption percentage and increased fecal excretion (ECI 2008).

In human studies, Turnlund et al. (1989) administered 12 young men with three different copper dietary doses. Mean absorption values were $\sim 55 \%$ for $0.9 \mathrm{mg} \mathrm{Cu} / \mathrm{day}, 36 \%$ for $1.99 \mathrm{mg} \mathrm{Cu} /$ day, and $12 \%$ for $7.78 \mathrm{mg} \mathrm{Cu} /$ day. Similar to the rat studies mentioned above, the results indicate that decreased copper absorption occurs with increasing dietary copper. Over the course of the experiments, the overall internal copper balance was maintained at a relatively constant rate. This study shows that internal copper levels are first regulated through absorption, with a second regulatory action through biliary excretion and fecal loss. In a similar study, Turnlund et al. (2005) performed a long-term copper dietary experiment in nine men (ages 26-49). Absorption ranged between 29 and $40 \%$ and was dependent on the dose of copper given, with higher absorption at the lower dose $(0.65-2.2 \mathrm{mg} \mathrm{Cu} /$ day). Studies have also been conducted on the effects of other dietary constituents on absorption, such as zinc, ascorbic acid, and fiber, in which no clear associations were found (ECI 2008), though some studies indicate that zinc and iron are antagonistic to copper absorption (ECI 2008).

Numerous studies indicate that dietary trace mineral exposure is affected by the mineral content and its bioavailability in different food matrices. Vegetarian diets are reported to contain more trace minerals, such as copper and manganese, compared with non-vegetarian diets (Hunt 2003). However, research indicating no differences in copper plasma levels between vegetarians and nonvegetarians or even higher $\mathrm{Cu}$ exposures from vegetarian diets, likely reflect differences in bioavailability as well as copper concentration among food types (KrajčovičováKudláčková et al. 1995; Hunt 2003; Van den Berghe and Klomp 2009). Earlier work indicated high amounts of fiber and phytate in plant-based foods reduces copper bioavailability compared with meat-based diets (Srikumar et al. 1992 b). Based on this finding and $\sim 25 \%$ reduction in copper bioavailability in two Wilson's disease patients on a vegetarian diet, vegetarian diets have been proposed as a part of treatment for Wilson's disease (Brewer et al. 1993). Nevertheless, in studies in rats, cooked food with high protein content had lower copper absorption when compared with vegetable and other meat sources (Johnson and Lee 1988; Wapnir 1998), whereas a high-meat diet resulted in higher excretion of copper in the feces compared with the low-meat diet, likely related to increased biliary excretion (Hunt et al. 1995). Hunt et al. (1995) indicated that, despite changes in copper availability based on diets, homeostasis maintains a relatively constant copper balance. Bost et al. (2016) reported that a range of dietary copper intake $(0.57-68 \mathrm{mg} / \mathrm{day}) \mathrm{did}$ not affect copper concentrations in plasma.

Other health issues, such as hypertension, also impact copper plasma levels (Srikumar et al. 1992a). This body of research (Hunt et al. 1995; Hunt 2003; Johnson and Lee 1988; Krajčovičová-Kudláčková et al. 1995; Srikumar et al. 1992b; Wapnir 1998) indicates that diet, bioavailability, and copper dysregulation may have various impacts and potential interactions affecting copper uptake and essentiality. ECI (2008) determined that, based on limited information on bioavailability and the absorption rate of other copper compounds, copper sulfate $\left(\mathrm{CuSO}_{4}\right)$ (which is one of the more soluble forms) can be used as representative for copper compounds when conducting risk assessments. More information on bioavailability and water solubility, such as for multiple forms of copper, can be found in section 2 of the Supplementary Information.

Fecal elimination after biliary secretion of copper complexed to organic ligands is documented as the primary route of copper excretion in laboratory animals (ECI 2008; Johnson 1988; Van den Berg et al. 1994). An estimated 80-90\% of biliary copper is excreted in the feces in humans (Winge and Mehra 1990). Winge and Mehra (1990) also demonstrate that fecal elimination is a key to maintaining homeostatic copper levels in the liver and is a more important mechanism for copper regulation than absorption. No studies have measured elimination through urine, saliva, sweat, or hair according to ECI (2008) and our review of subsequent literature. It appears that little additional information quantifying absorption and elimination percentages has been published in the past decade. In addition, no publications were found that discuss what proportion of copper forms, $(\mathrm{Cu}$ (I) and $\mathrm{Cu}(\mathrm{II})$, is absorbed by the gastrointestinal tract through active or passive transport pathways.

\section{Distribution and Metabolism}

Laboratory animal studies support a two-stage model of copper transport. As copper enters the bloodstream after absorption in the gastrointestinal tract, ionic copper complexes with plasma proteins such as albumin, ceruloplasmin, and transcuprein and is transported through portal circulation to the liver (NRC 2000). Ceruloplasmin 
carries $60-95 \%$ of copper found in the blood serum (IOM 2001). While normal values for ceruloplasmin and blood serum have been identified, these measures are subject to rapid changes based on diet and have not served as reliable biomonitoring indicators of exposure. The normal range of copper found in blood serum is $0.635-1.59 \mathrm{mg} \mathrm{Cu} / \mathrm{L}$ (IOM 2001). Albumin is the most abundant blood protein with a high affinity and capacity for copper binding $(600 \mathrm{mg} / \mathrm{L}$ of blood plasma), which together with other metal binding proteins, results in very little "free" ionic copper in blood (Linder 2016). Uptake of albumin-bound $\mathrm{Cu}$ (II) across cellular barriers also occurs via cell surface reductases and Ctr1 and other unidentified transporters (Lee et al. 2002; Linder 2016). The liver also complexes any free copper ions with proteins that are then secreted into the bloodstream, stored in the liver, or excreted in bile to the gastrointestinal tract, thereby maintaining homeostasis (ECI 2008). Within a cell, copper is stored complexed to a metal binding protein, metallothionein. In addition, proteins found in the cell cytoplasm, called metallochaperones, bind copper and prevent the release and accumulation of the more toxic free copper ions within a cell, while providing necessary copper delivery to intracellular locations (ECI 2008). As noted above for Menke's and Wilson's Dieases, the regulatory proteins ATP7A and ATP7B, respectively, are instrumental in transporting copper out of cells (e.g., from intestinal cells to portal circulation and across the blood-brain barrier for ATP7A; from the liver into bile for ATP7B).

Numerous distribution and metabolism studies have been conducted in mammals. In Sprague-Dawley and Fisher female rats, copper is first found bound to albumin with peak liver concentrations at 6 and $24 \mathrm{~h}$, representing $2-40 \%$ of the dose. In parallel, an increase of copper with ceruloplasmin was measured. After $24 \mathrm{~h}$, no copper was measured in albumin. Throughout the study, copper-ceruloplasmin represented $50 \%$ of the dose, and $>90 \%$ of the dose was found in plasma proteins, including ceruloplasmin. Copper was also detected in other organs besides the liver and kidney, such as the skeletal muscle (18\%), brain (2-3\%), and heart (8\%) (Weiss and Linder 1985).

The distribution and metabolism of copper in humans is similar to that found in animals. The liver and brain are the organs with the highest concentrations of copper with muscle overall containing the largest amount of copper on a total mass basis (ECI 2008).

\section{Noncancer Toxicity}

\section{Acute Toxicity}

Copper toxicity typically results from the production of reactive oxygen species during redox reactions involving excess free or ionic copper forms, and from sufficient accumulation to overwhelm protein-binding capacity (Gaetke et al. 2014). In humans, acute effects of copper ingestion include gastrointestinal symptoms such as nausea or abdominal pain. Olivares et al. (2001) gave men and women $(n=61$, total) a single dose of $0-12 \mathrm{mg} \mathrm{Cu} / \mathrm{L}$ as $\mathrm{CuSO}_{4}$ in deionized drinking water using a randomized design, followed by collection of self-reported perceived symptoms at 15 and $60 \mathrm{~min}$ and $24 \mathrm{~h}$. Nausea was most commonly reported immediately following the dose, and $12 \mathrm{mg} \mathrm{Cu} / \mathrm{L}$ had the highest percentage of nausea reported (21\%). The lowest-observed-adverse-effects level (LOAEL) was $4 \mathrm{mg} \mathrm{Cu} / \mathrm{L}$, and the no-observed-adverse-effects level (NOAEL) was $2 \mathrm{mg} \mathrm{Cu} / \mathrm{L}$. Nausea was reported in $76 \%$ of the volunteers.

Studies by Araya et al. (2001, 2003a) are the most comprehensive investigations of the levels of copper in water that cause acute gastrointestinal effects. These studies were used by ECI (2008) to derive the LOAEL and NOAEL used for copper in drinking water. Araya et al. (2001) used a similar study design as reported in Olivares et al. (2001). Doses of copper were given once a week for 5 weeks at $0-8 \mathrm{mg} \mathrm{Cu} / \mathrm{L}$ to a total of 179 volunteers (men and women). Up to $18 \%$ of volunteers reported nausea at the $8 \mathrm{mg} \mathrm{Cu} / \mathrm{L}$ dose. In Araya et al. (2003a), a total of 249 women in Chile, the United States, Northern Ireland, and China were administered a single, oral bolus dose in bottled water at $0,2,4$, 6 , or $8 \mathrm{mg} \mathrm{Cu} / \mathrm{L}$. The study was double-blind with each person as their own control. Consistent with the other two studies, nausea was the most common and earliest symptom in Araya et al. (2003a) and occurred within $15 \mathrm{~min}$ of ingestion. Reports of nausea increased with higher doses, and nausea was the most frequently reported symptom. The LOAEL for nausea was $6 \mathrm{mg} \mathrm{Cu} / \mathrm{L}$ and the NOAEL was $4 \mathrm{mg} \mathrm{Cu} / \mathrm{L}$. Other symptoms were reported less frequently and included abdominal pain, vomiting, and/or diarrhea. Gastrointestinal effects occurred immediately and stopped once the exposure ceased (Araya et al. 2003a). These controlled human experimental trials conducted with multiple international populations allow for a reliable identification of a copper concentration in drinking water that does not cause irritation to the gastrointestinal tract leading to symptoms.

\section{Irritation and Sensitization}

Irritation and sensitization associated with skin contact are less relevant for assessing risk from copper via the oral exposure pathway. Stomach irritation from water ingestion is addressed in the sections relating to acute toxicity and repeated-dose toxicity. Sensitization, whether oral or dermal, does not appear to be relevant for copper (ECI 2008). An additional summary of data on irritation and 
sensitization is provided in section 3.0 of the Supplementary Information.

\section{Repeated-Dose Toxicity}

\section{Human experimental studies}

Several repeated-dose studies of copper exposure in drinking water or in other soluble forms have been conducted in humans (summarized in Table 1). Additional details on the human water ingestion studies are presented in Supplementary Table S2. One of the most robust studies is a cohort study in Chile (Olivares et al. 1998) in which 128 formulaor breast-fed infants, 3-12 months old, were assigned to a copper-supplemented $(2 \mathrm{mg} \mathrm{Cu} / \mathrm{L}$ in drinking water using $\left.\mathrm{CuSO}_{4}\right)$ or control group $(<0.1 \mathrm{mg} \mathrm{Cu} / \mathrm{L})$. Drinking water for each group was also used in making formula and in food preparation. Formula-fed infants were weaned at 3 months, and breast-fed infants started solid food at 6 months, with interim formula provided when necessary. Drinking water for the mothers contained $2 \mathrm{mg} \mathrm{Cu} / \mathrm{L}$ and the control contained $0.1 \mathrm{mg} \mathrm{Cu} / \mathrm{L}$. The water concentration of $2 \mathrm{mg} \mathrm{Cu} / \mathrm{L}$ was selected for this study based on the WHO guideline at the time. Mothers of the breast-fed infants also consumed the same water concentrations as the infant. Water consumption was recorded, and blood samples at 6, 9, and 12 months were analyzed for biochemical parameters (serum copper level, ceruloplasmin level, erythrocyte enzyme activity, and metallothionein), liver function (enzymatic activity, serum bilirubin), gastrointestinal symptoms, and respiratory disorder. Infants in the $2 \mathrm{mg} \mathrm{Cu} / \mathrm{L}$ group had elevated ceruloplasmin activity at 9 months. No effects were observed for growth or morbidity. A NOAEL of $2 \mathrm{mg} \mathrm{Cu} / \mathrm{L}$ in drinking water was determined with endpoints of biochemical indicators for liver toxicity and gastrointestinal symptoms; however, participant dropout was higher in the $2 \mathrm{mg} \mathrm{Cu} / \mathrm{L}$ group, which may have resulted in under-reporting of symptoms in this study.

Other studies have investigated gastrointestinal and liver effects of copper on adults such as nausea, vomiting, and liver enzyme function. The study by Pizarro et al. (1999) consisted of 60 adult Chilean women orally ingesting 0,1 , 3 , or $5 \mathrm{mg} \mathrm{Cu} / \mathrm{L}$ (prepared with $\mathrm{CuSO}_{4}$ ) for 2 weeks using a "Latin-square" design. Women prepared water at home with the specified dose and logged total amount of water consumed at the end of each day. The 2-week exposure was followed by 1 week of no exposure. In addition to assessing gastrointestinal symptoms, blood samples were analyzed for serum copper and ceruloplasmin levels and liver function via enzymatic activity, which showed no changes after the 2 weeks of exposure. The incidence of gastrointestinal symptoms was $5 \%(0 \mathrm{mg} \mathrm{Cu} / \mathrm{L}), 8 \%(1 \mathrm{mg} \mathrm{Cu} / \mathrm{L}), 23 \%$ (3 mg Cu/L), and 22\% (5 mg Cu/L). Acute gastrointestinal effects in women were observed at $3 \mathrm{mg} \mathrm{Cu} / \mathrm{L}$ in drinking water, with an estimated NOAEL of $2 \mathrm{mg} \mathrm{Cu} / \mathrm{L}$ drinking water (Pizarro et al. 1999).

In a second study (Pizzaro et al. 2001), 45 adult Chilean women ingested $5 \mathrm{mg} / \mathrm{L}$ of total copper with different ratios of soluble $\left(\mathrm{CuSO}_{4}\right)$ to insoluble (copper (II) oxide) $(0: 5,1: 4$, $2: 3,3: 2$, and 5:0) for 1 week followed by a 1-week break, repeating for a total of 9 weeks. The study investigated the same effects as in Pizarro et al. (1999) (liver, gastrointestinal effects, and $\mathrm{Cu}$ homeostasis). The various ratios of copper forms did not affect gastrointestinal symptoms with similar symptoms observed for all ratios. Acute gastrointestinal symptoms were caused by both soluble and insoluble copper, indicating that, regardless of the ingested form, ionic copper is formed in the stomach, thereby resulting in irritation. This information seems to contradict reported differences in copper bioavailability between soluble and insoluble or less soluble forms (section 2.0 in the Supplementary Information); however, other factors likely influence dissolution rate and, hence, gastrointestinal bioavailability for copper in soil should be considered (Intawongse and Dean 2006).

In Araya et al. (2001), 179 men and women from the Unites States, the United Kingdom, and Chile ingested 0, 2, 4,6 , or $8 \mathrm{mg} \mathrm{Cu} / \mathrm{L}$ in a single, weekly bolus dose of deionized water over 5 weeks prepared with $\mathrm{CuSO}_{4}$. Gastrointestinal effects were self-reported $15 \mathrm{~min}, 1$, and $24 \mathrm{~h}$ after administration. The LOAEL was determined at $6 \mathrm{mg} \mathrm{Cu} / \mathrm{L}$, and the NOAEL for gastrointestinal effects and nausea was $4 \mathrm{mg} \mathrm{Cu} / \mathrm{L}$. Nausea was the first and most common symptom reported in the study.

In a larger multinational study by Araya et al. 2003b, 1365 adults (study centers in the Unites States, Ireland, Chile, and China; $N=58-73 /$ center) used tap water daily over 2 months with $0.01,2$, 4 , or $6 \mathrm{mg} \mathrm{Cu} / \mathrm{L}$ in a doubleblind study. Daily usage and ingestion included drinking and preparation of soups, foods, and/or beverages. Gastrointestinal effects were self-reported daily, and field workers visited homes every other day to consult with participants. After 2 months, blood samples were drawn from 60 participants from each experimental group for measurement of copper status (serum copper concentration, ceruloplasmin concentration, and copper-containing enzyme [superoxide dismutase] activity). Gastrointestinal effects were reported for all groups including the control, as in other studies that might be attributed to background symptoms (Araya et al. 2001, 2003a; Pizarro et al. 1999, 2001). A statistically significant increase in gastrointestinal symptoms was identified at $6 \mathrm{mg} \mathrm{Cu} / \mathrm{L}$ with the NOAEL reported as $4 \mathrm{mg} \mathrm{Cu} / \mathrm{L}$. Changes in serum copper concentration or liver enzyme levels were not detectable, indicating copper homeostasis and liver function were not affected, consistent with low likelihood of liver toxicosis for most people at these 


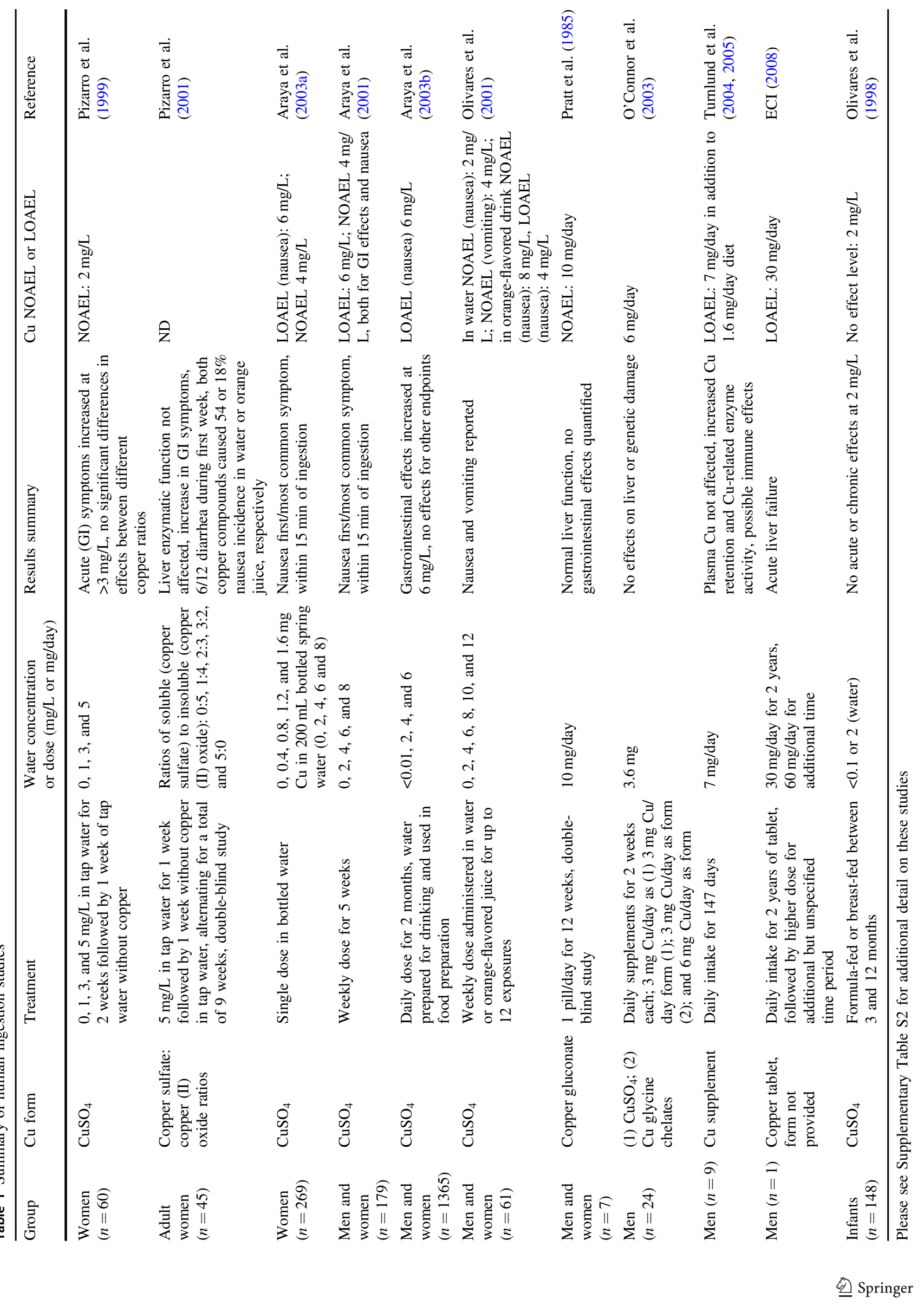


elevated water copper levels in addition to background dietary copper.

Studies from Araya et al. (2001, 2003b), Olivares et al. (1998, 2001), and Pizarro et al. (1999, 2001) helped determine the dose-response relationship between copper in drinking water and acute gastrointestinal effects (WHO 2004). Based on these new studies the WHO upgraded their provisional guideline of $2 \mathrm{mg} / \mathrm{L}$ to an established guideline due to the reduction in dose-response uncertainties (WHO 2004). The $2 \mathrm{mg} / \mathrm{L}$ value is based on consumption of $2-3 \mathrm{~L}$ of water per day, the use of dietary supplements, and copper ingestion from food (WHO 2004) without exceeding the tolerable upper intake level of $10 \mathrm{mg} \mathrm{Cu}$ /day (IOM 2001) or leading to gastrointestinal effects (WHO 2004).

Effects of copper dose on internal copper regulation and possible systemic effects have been assessed in a few experimental studies of human subjects. Turnlund et al. (2004, 2005) evaluated copper status, copper-related enzyme levels, and immune system parameters of nine men (ages 26-49 years old) who consumed a diet with $1.6 \mathrm{mg} \mathrm{Cu} /$ day for 18 days $(0.02 \mathrm{mg} \mathrm{Cu} / \mathrm{kg} \mathrm{BW} /$ day based on $75 \mathrm{~kg}$ average body weight of subjects), followed by an uncontrolled diet and copper supplements at $7 \mathrm{mg} \mathrm{Cu} /$ day $(0.093 \mathrm{mg} \mathrm{Cu} / \mathrm{kg} \mathrm{BW} /$ day) for 129 days, and finally 18 days of $6.2 \mathrm{mg} \mathrm{Cu} /$ day supplement and a $1.6 \mathrm{mg} \mathrm{Cu} /$ day diet $(0.1 \mathrm{mg} \mathrm{Cu} / \mathrm{kw}$ BW/day). Calculated copper retention (based on absorption and excretion of radiolabeled copper) was near zero at $1.6 \mathrm{mg} \mathrm{Cu} /$ day diet intake but retention increased to $0.67 \mathrm{mg} \mathrm{Cu} /$ day after the $6.2 \mathrm{mg} \mathrm{Cu}$ /day supplement period. Plasma copper was not affected by the higher copper supplementation, but activity of ceruloplasmin, benzylamine oxidase, and superoxide dismutase increased (Turnlund et al. 2004). Some changes were also observed in the composition of white cell counts, although total white cell numbers were not affected. Antibody titers of three influenza strains were lower after vaccination in the copper-exposed subjects compared with 10 control subjects; however, large variation in these levels resulted in statistical significance for titers of only one of the strains. Other changes in measures of immune parameters or responses were not statistically significant. These results may also have been affected by the multiple comparisons being tested and the small subject numbers.

Understanding whether copper supplements increase copper exposure sufficiently to cause adverse effects is important. The primary reported effect of chronic elevated copper intake is liver damage (IOM 2001). To understand copper supplementation and its effects on the liver, a double-blind repeated crossover trial with 24 subjects was used for a total of 6 weeks (O'Connor et al. 2003). A total of three supplements were each given for 2 weeks for a total of 6 weeks in the following order and form: $3 \mathrm{mg} \mathrm{Cu} /$ day in the form of $\mathrm{CuSO}_{4}$ (divalent form), $3 \mathrm{mg} \mathrm{Cu} /$ day as $\mathrm{Cu}$ glycine chelates (divalent form), and $6 \mathrm{mg} \mathrm{Cu}$ /day as $\mathrm{Cu}$ glycine chelates. A modified Comet assay and assessment of liver enzymes found no significant alteration of the liver or DNA from copper supplementation, even at an ingestion of $6 \mathrm{mg} \mathrm{Cu} /$ day every day for 6 weeks, or at approximately six times the normal intake (O'Connor et al. 2003).

The study used by IOM to develop the tolerable upper intake level selected liver toxicity as the endpoint with a total of seven human test subjects using a double-blind study with $10 \mathrm{mg} \mathrm{Cu} /$ day as copper gluconate (divalent form) or a placebo for 12 weeks (Pratt et al. 1985). No liver damage or gastrointestinal effects were reported. Overall, although no liver toxicity occurred with these repeated-dose studies of copper supplements, the few studies and small study sample sizes limit conclusions about the exact conditions (dose, length of exposure, form of copper, and individual susceptibility) under which liver damage might or might not occur.

\section{Toxicity studies in animals}

A number of repeated-dose studies have been conducted in animals, generally at doses well above those associated with acute nausea in humans from drinking water. The animal studies provide additional information on subchronic and chronic toxicity that is generally less available in human case and experimental studies. The two-animal repeateddose studies summarized below are considered the most informative repeated exposure studies due to the robust, guideline-compliant study designs (ECI 2008). Additional details on these studies, as well as other animal repeateddose studies, are presented in Tables $\mathrm{S} 2$ and $\mathrm{S} 4$, and section 4.0 of the Supplementary Information.

The US National Toxicology Program (NTP) conducted 2-week dietary and drinking water exposure studies and 13week dietary studies with $\mathrm{CuSO}_{4}$ in $\mathrm{F} 344 / \mathrm{N}$ rats and $\mathrm{B}_{6} 3 \mathrm{~F}_{1}$ mice (Hébert 1993). In the 2-week NTP drinking water exposure study, rats (5/sex/group) were orally administered drinking water with copper sulfate $\left(\mathrm{CuSO}_{4}\right)$ corresponding to copper concentrations of 76, 254, 762, 2543, or $7629 \mathrm{mg} \mathrm{Cu} / \mathrm{L}$. The estimated exposure levels were 10 , 29, 45, 36, and $97 \mathrm{mg} \mathrm{Cu} / \mathrm{kg} \mathrm{BW/day} \mathrm{for} \mathrm{males} \mathrm{and} \mathrm{10,} \mathrm{26,}$ 31,31 , and $71 \mathrm{mg} \mathrm{Cu} / \mathrm{kg} \mathrm{BW} /$ day for females). Dose groups at or above $45 \mathrm{mg} \mathrm{Cu} / \mathrm{kg} \mathrm{BW} /$ day for males and $31 \mathrm{mg} \mathrm{Cu} / \mathrm{kg}$ BW/day $(762 \mathrm{mg} \mathrm{Cu} / \mathrm{L})$ for females experienced numerous effects such as death and organ weight loss. Additional effects consistent with dehydration from reduced water consumption were also reported. An identical drinking water study was performed in $\mathrm{B}_{6} \mathrm{C} 3 \mathrm{~F}_{1}$ mice and results between the two studies were consistent. Equivalent toxicity in mice was observed at 58 and $62 \mathrm{mg} \mathrm{Cu} / \mathrm{kg} \mathrm{BW} /$ day $(762 \mathrm{mg} \mathrm{Cu} / \mathrm{L})$ in male and female mice. 
In the 2-week NTP feeding study, Fischer rats were orally administered $255,509,1018,2036$, or $4072 \mathrm{mg} \mathrm{Cu} /$ $\mathrm{kg} \mathrm{diet}{ }^{4}$ (equivalent to 23.4, 45.8, 92.4, 197.8, and $324.5 \mathrm{mg}$ $\mathrm{Cu} / \mathrm{kg} \mathrm{BW/day} \mathrm{for} \mathrm{males} \mathrm{and} \mathrm{22.7,} \mathrm{44.3,} \mathrm{93.4,} \mathrm{195.7,} \mathrm{and}$ $285.3 \mathrm{mg} \mathrm{Cu} / \mathrm{kg} \mathrm{BW} /$ day for females) (Hébert et al. 1993; Hébert 1993). Feed was available to the rats for 15 days. At $\geq 197.8 \mathrm{mg} \mathrm{CuSO} / \mathrm{kg} \mathrm{BW} /$ day for males and $\geq 195.7 \mathrm{mg}$ $\mathrm{CuSO}_{4} / \mathrm{kg} \mathrm{BW/day} \mathrm{for} \mathrm{females,} \mathrm{body} \mathrm{weight} \mathrm{reductions}$ between 66 and $92 \%$ in male and female rats occurred due to a reduction in food consumption in addition to direct toxicity. At $509 \mathrm{mg} \mathrm{Cu} / \mathrm{kg}$ diet, histopathological changes to the forestomach were observed, and hepatic lesions were noted at the two highest doses. Cell depletion in bone marrow and spleen occurred at $\geq 197.8 \mathrm{mg} \mathrm{CuSO}_{4} / \mathrm{kg} \mathrm{BW/}$ day for males and $\geq 195.7 \mathrm{mg} \mathrm{CuSO}_{4} / \mathrm{kg} \mathrm{BW} /$ day for females, respectively. No deaths occurred. Inflammation of the liver was noted in male rats above $197.8 \mathrm{mg} \mathrm{CuSO}_{4} / \mathrm{kg}$ BW/day. An identical study was performed for B6C3F1 mice. The NOAEL for forestomach lesions was determined at 23.4 and $22.7 \mathrm{mg} \mathrm{Cu} / \mathrm{kg} \mathrm{BW} /$ day for male and female rats and at 42.8 and $53.5 \mathrm{mg} \mathrm{Cu} / \mathrm{kg} \mathrm{BW} /$ day for male and female mice (Hébert et al. 1993; Hébert 1993).

The 13-week NTP feeding study in rats used diet concentrations of $127,255,509,1018$, and $2036 \mathrm{mg} \mathrm{Cu} / \mathrm{kg}$ feed (8.1, 16.3, 32.8, 65.9, and $140.2 \mathrm{mg} \mathrm{Cu} / \mathrm{kg} \mathrm{BW/day} \mathrm{for}$ males and 8.7, 17.3, 34.4, 68.0, and $134.4 \mathrm{mg} \mathrm{Cu} / \mathrm{kg} \mathrm{BW/}$ day for females) (Hébert 1993). No exposure-related deaths occurred. Weight loss was significant at the two highest doses. Effects at $\geq 509 \mathrm{mg} \mathrm{Cu} / \mathrm{kg}$ feed included decreases in cell volume and hemoglobin, increases in enzymatic activity, and forestomach, liver, and kidney lesions. A significant dose-related increase of copper concentration occurred in the liver and kidney over the dose range. The NOAEL for forestomach, kidney, and liver effects in rats was determined to be $16.3 \mathrm{mg} \mathrm{Cu} / \mathrm{kg} \mathrm{BW} /$ day for male rats and the NOAEL for forestomach lesions for female rats was $17.3 \mathrm{mg} \mathrm{Cu} / \mathrm{kg} \mathrm{BW} /$ day. An identical study was performed in $\mathrm{B} 6 \mathrm{C} 3 \mathrm{~F}_{1}$ mice, though no liver or kidney effects were observed (Hébert 1993). The NOAEL for forestomach lesions in mice was 97.2 and $125.7 \mathrm{mg} \mathrm{Cu} / \mathrm{kg} \mathrm{BW} /$ day for males and females, respectively. In general, liver effects in rats were only seen at doses $>16.3 \mathrm{mg} \mathrm{Cu} / \mathrm{kg} \mathrm{BW} /$ day.

In a chronic copper feeding study in C57BL/6J mice, 1month-old mice were given $317 \mathrm{mg} \mathrm{Cu} / \mathrm{L}$ as copper gluconate in drinking water until various ages, ranging between 31 and 700 days (Massie and Aiello 1984). Mean survival was reduced by $14.4 \%$ and the maximum lifespan was reduced by $12.8 \%$ (Massie and Aiello 1984). In general, the NOAEL dose was the same for both gastrointestinal effects and internal organ effects (e.g., liver) in the more sensitive

\footnotetext{
${ }_{4}^{\mathrm{mg} \mathrm{Cu} / \mathrm{kg} \text { diet }}$ converted to $\mathrm{mg} \mathrm{Cu} / \mathrm{kg} \mathrm{BW} /$ day by assuming a rat body weight of $\sim 11 \mathrm{~kg}$.
}

species, rats. Other repeated-dose studies are summarized in Supplementary Table S2 and in the review of reproductive and developmental toxicity studies below.

\section{Investigation of Liver Toxicosis in Populations Exposed to Elevated Copper}

Studies of Indian childhood cirrhosis (ICC) and Tyrolean infantile cirrhosis are the primary reported examples of childhood liver disease resulting from exposure to high copper concentrations along with suspected genetic susceptibility (NRC 2000). In certain regions in India, liver cirrhosis occurred in some infants and young children at a time when milk was stored in copper or brass containers (NRC 2000; Uauy et al. 2008; Nayak and Chitale 2013). High copper concentrations found in the livers of children were quickly reversed with a reduction in exposure and treatment. Clinical features and symptoms of the disease, however, differed from those of Wilson's disease patients. Moreover, age-matched asymptomatic siblings of ICC cases and control children also showed increases in copper and copper-binding proteins in liver tissue but without the structural and functional changes observed in the ICC cases. With the elimination of storing milk in materials containing copper, the disease frequency decreased, implicating copper in the etiology of the disease, although the association has been noted as circumstantial (Sriramachari and Nayak 2008). It is thought that susceptibility was related to an autosomal recessive trait because some siblings were also affected, whereas the parents of affected children were not affected in childhood (NRC 2000). However, examination of the pedigree of families with ICC and age-matched controls revealed that genetic susceptibility is likely based on multiple factors, rather than a single factor, as no clear evidence of autosomal recessive, partial sex linkage, or double recessive traits was found (Naya and Chitale 2013). No clear documentation exists for the amount of copper infants were exposed to in the Indian childhood liver toxicosis case study; however, one study tried to replicate copper concentrations potentially available through the use of brass vessels for milk storage and found up to $6.21 \mathrm{mg}$ $\mathrm{Cu} / \mathrm{L}$ in milk after $6 \mathrm{~h}$ (O'Neill and Tanner 1989), or $0.93 \pm 0.1 \mathrm{mg} \mathrm{Cu} / \mathrm{kg} \mathrm{BW} /$ day for an exposure of a child consuming milk at a rate of $150 \mathrm{~mL} / \mathrm{kg} \mathrm{BW} /$ day.

Further investigation of the origin of the disease by a multicenter study in India indicated that copper may not be the cause in all ICC cases and that excessive liver copper may also be the result of hepatic injury from some other factors (Nayak and Chitale 2013; Sriramachari and Nayak 2008). This collaborative study across six research centers was conducted in the 1980 s to clarify the cause of ICC (Nayak and Chitale 2013; Sriramachari and Nayak 2008). Based on a review of 885 children with a liver biopsy, 227 
cases of definite ICC were compared with 426 non-ICC control cases for use of "copper yielding utensils." In two research centers, none of the ICC cases used these utensils, compared with less than $2 \%$ of controls. In three research centers, use of these utensils in study subjects was 15-20\% with no difference between ICC cases and controls. The remaining research center reported greater utensil use that was not statistically different between ICC cases $(55 \%)$ and controls $(52 \%)$. About $10 \%$ of definite ICC cases had no possible prior source of excess copper exposure. Asymptomatic siblings with some accumulation of copper in their liver (although not as high as ICC cases) showed no evidence of toxicity and had a decline in copper to normal levels after removal of copper-containing utensils. Hepatic liver concentrations increased in the later stages of ICC rather than in the early stages, suggesting, along with the lack of evidence of higher exogenous copper exposure in most ICC cases, that copper accumulation was a result rather than the cause of the disease. More likely etiologies for ICC were thought to be poor diet quality or postpartum herbal supplements given to new mothers and infants that resulted in adverse effects on the liver rather than toxicity from excess exogenous copper exposure (Nayak and Chitale 2013; Sriramachari and Nayak 2008).

In Tyrolean infantile cirrhosis, elevated copper exposure through heating milk in copper pots or the use of copper utensils was associated with liver cirrhosis and 138 pediatric deaths in an area of western Austria between 1900 and 1980 (NRC 2000; Müller et al. 1996; Uauy et al. 2008). The symptoms were indistinguishable from ICC. Liver cirrhosis appeared to run in families, although not all children within a family were affected. Both affected and unaffected siblings consumed the same milk, which was retrospectively estimated to have a copper concentration of 10.5-63.3 mg Cu/L when prepared and boiled for $20 \mathrm{~min}$ in brass and copper pots (Müller et al. 1996). By comparison, reported copper concentrations in breast milk range from $\sim 0.2-1 \mathrm{mg} \mathrm{Cu} / \mathrm{L}$ and concentrations appear to be highest soon after birth followed by a decline during the first year (ATSDR 2004). The siblings without liver toxicosis were unaffected at doses estimated to be 8-49 times higher than the current $1.3 \mathrm{mg} \mathrm{Cu} / \mathrm{L} \mathrm{EPA}$ action level for drinking water.

Other studies have examined whether populations with higher copper levels in drinking water have resulted in liver toxicosis in infants and children. One study was conducted in three towns in Massachusetts from 1969-1991 with 8.5-8.8 mg Cu/L in drinking water (Scheinberg and Sternlieb 1994). A total of 2788 children under the age of 6 were followed during the course of 23 years to determine the total number of infantile deaths and infantile deaths relating to liver disease. A total of 135 deaths occurred but none were attributed to cirrhosis or any type of liver disease, despite drinking water levels that were higher than the $1.3 \mathrm{mg} \mathrm{Cu} / \mathrm{L}$ EPA action level by 6.5-6.8 times.

A study in Berlin, Germany, tested water samples from 2944 households with infants (Zietz et al. 2003). A subset of 541 infants consuming tap water with composite water concentrations in their household above $0.8 \mathrm{mg} \mathrm{Cu} / \mathrm{L}$ (maximum $4.2 \mathrm{mg} \mathrm{Cu} / \mathrm{L}$ ) were selected for medical examination. Nearly all of these 541 infants were examined, none of whom was diagnosed with liver disease. A subset $(N=$ 183) also received an analysis of serum copper concentration, liver enzyme levels, total bilirubin, and ceruloplasmin, the results of which were not associated with copper exposure. Another case study in Germany indicated that symptoms in 22 children exposed to drinking water containing $0.4-15.5 \mathrm{mg} \mathrm{Cu} / \mathrm{L}$ were attributed to liver toxicosis, though the water concentrations were not measured until a few months after symptoms were observed (IPCS 1998), and, as for ICC, cases of liver toxicosis are not necessarily associated with copper exposure. Of the 22 children, 13 fatalities were recorded, though fatalities could not be linked to a specific copper concentration in water causing the liver toxicosis. Other cases of idiopathic copper toxicosis have occurred in Mexico (Cabrera-Muñoz et al. 2010) and in Japan (Hayashi et al. 2012).

Brewer (2000) postulated an underlying basis for genetic susceptibility to excess copper exposure may exist among those who are heterozygous for Wilson's disease. In particular, Brewer (2000) noted that a few of these individuals show signs of alterations in copper metabolism that appear to approach those with Wilson's disease. These individuals are not affected at normal copper exposures but are hypothesized to be more sensitive to excess copper accumulation as exposures increase. Although Wilson's disease is relatively rare ( 1 in 50,000 or 1 in 100,000 live births), an estimated $1-2 \%$ of the worldwide human population is a heterozygous carrier of this disease (Das and Ray 2006; Gromadzka et al. 2010; Gollan and Gollan 1998). Gromadzka et al. (2010) examined copper metabolism and function parameters in 68 heterozygous carriers of Wilson's disease and 31 control individuals. Heterozygote carriers had parameters largely within normal limits with three individuals showing ceruloplasmin levels that were slightly lower than the reference level. As a group, ceruloplasmin levels of the heterozygotes were $75 \%$ of the control group, but serum copper levels and urinary copper excretion were not statistically significantly different (Fig. 1 in Gromadzka et al. 2010). Gromadzka et al. (2010) also noted that internal regulation of copper depends on a number of other genetically determined regulatory factors and that any combination of regulatory factors may compensate in deficiencies associated with Wilson's disease heterozygosity. No additional research has emerged to further evaluate the hypothesis of environmental sensitivity to copper by 
heterozygote carriers of Wilson's disease, nor have additional cases of pediatric liver toxicosis with elevated copper exposure been published, despite the common use of copper in consumer products and the greater prevalence of Wilson's disease heterozygotes than for Wilson's disease patients.

Concerns for potential susceptibility to liver toxicosis at elevated copper levels led the NRC to recommend that the $1.3 \mathrm{mg} \mathrm{Cu} / \mathrm{L}$ EPA action level for copper not be increased (NRC 2000). The scientific literature since does not provide additional evidence to better define a level at which liver toxicosis might occur in susceptible subgroups, although the majority of the evidence involves copper levels in water or milk well in excess of the NOAEL levels defined for acute gastrointestinal effects (i.e., $4 \mathrm{mg} \mathrm{Cu} / \mathrm{L}$ ). Exposure to excess copper is most likely through the use of copper piping for drinking water used in the public water supply and in homes (Uauy et al. 2008).

\section{Reproductive Toxicity}

For both reproductive and developmental effects of copper, animal studies indicate that effects to offspring occur at doses that also cause maternal toxicity. Information on potential reproductive toxicity of copper derives primarily from a two-generation rat reproductive toxicity study conducted with $\mathrm{CuSO}_{4}$ (ECI 2008). The source study is unpublished but was undertaken for a European Regulation on Registration, Evaluation, Authorization, and Restriction of Chemicals submission and is summarized in detail in ECI (2008). The study was conducted under good laboratory practices and in accordance with standard Organization for Economic Co-operation and Development (OECD) test guidelines. Parental generation (P1) male and female Sprague-Dawley rats (30/sex/group) were fed diets containing $0,25.4,127,254$, and $381 \mathrm{mg} \mathrm{Cu} / \mathrm{kg}$ for premating P1 males and 0, 1.92, 9.6, 19.1, and $29.5 \mathrm{mg} \mathrm{CuSO}_{4} / \mathrm{kg}$ BW/day for premating P1 females for at least 70 days before mating and, for females, continuing through gestation and weaning at postpartum day 21. Male and female rats from F1 litters (30/sex/group) were randomly selected to continue with dietary treatment until mating and, for F1 females, through gestation and weaning of F2 pups. Clinical observations, body weight, and food consumption were assessed at least weekly throughout the study. The study evaluated sperm quality and quantity, estrous cyclicity, mating, fertility, and implantation parameters, pup survival and development, sex ratio, sexual development, weight and gross pathology of reproductive and other organs, and histopathology of liver, brain, and reproductive organs. No treatment-related effects on any reproductive or developmental parameters were observed in any dose group for any generation. Thus, the NOAEL for reproductive toxicity was the highest dose group of $381 \mathrm{mg} \mathrm{Cu} / \mathrm{kg}$ (reported as a copper intake of $23.6-55.7 \mathrm{mg} \mathrm{Cu} / \mathrm{kg} \mathrm{BW} /$ day). The ECI (2008) summary notes decreased spleen weight for P1 females and F1 and F2 male and female weanlings in the highest dose group. Although not a reproductive effect, ECI (2008) identifies this as a treatment-related adverse effect with a NOAEL of $254 \mathrm{mg} \mathrm{Cu} / \mathrm{kg}(15.2-26.7 \mathrm{mg} \mathrm{Cu} / \mathrm{kg} \mathrm{BW} /$ day). The ECI (2008) summary of the unpublished study indicated that apparent changes in spleen weight were small (9-15\%) and not statistically significant for F1 weanlings, and potentially transient (spleen weight did not differ from controls in F1 adults). Rat spleen weight can be variable; however, the study authors also showed that F1 and F2 weanling spleen weights in this study were similar to historical controls for the laboratory.

The subchronic exposure study conducted by NTP provides additional information relevant to reproductive toxicity (Hébert 1993). In that study, the highest dietary $\mathrm{Cu}$ doses at $68 \mathrm{mg} \mathrm{Cu} / \mathrm{kg} \mathrm{BW} /$ day for rats and $536 \mathrm{mg} \mathrm{Cu} / \mathrm{kg}$ BW/day for mice did not affect male reproductive organ weights, spermatid or spermatozoal measurements, or estrous cyclicity. Other reproductive endpoints were not measured.

No human studies were identified that adequately evaluate copper exposure and reproductive endpoints. ECI (2008) cites two case-control studies that reported no association between drinking water copper concentrations and pregnancy outcomes, including spontaneous abortions, stillbirths, neonatal mortality, and congenital abnormalities (Aschengrau et al. 1989, 1993). Copper was one among many chemicals evaluated, and no data were available on individual exposures; samples were collected from the public water system, not individual taps. Thus, these studies have limited value for evaluating copper exposure.

\section{Developmental Toxicity}

The developmental toxicity study considered to have the most rigorous design is an unpublished report of a onegeneration prenatal developmental toxicity study on rabbits with copper hydroxide (details summarized in ECI 2008), conducted following OECD test method 414. This study administered $0,6,9$, and $18 \mathrm{mg} \mathrm{Cu} / \mathrm{kg} \mathrm{BW} /$ day by twice daily oral gavage to pregnant female New Zealand white rabbits (22/group) on gestational days 7 through 28 . Maternal toxicity occurred in both the 9 and $18 \mathrm{mg} \mathrm{Cu} / \mathrm{kg}$ BW/day dose groups, including weight loss and reduced food intake early in the treatment period. Although some recovery occurred at the end of the study, maternal body weight gain was 31 and $72 \%$ lower than controls in the midand high-dose groups, respectively, and food consumption was reduced 17 and $30 \%$ in the mid- and high-dose groups, respectively. In addition, three deaths and two abortions 
occurred in the high-dose group, possibly due to hemorrhages or ulcerative damage to the stomach lining observed in these three animals. The appetite suppression and associated weight loss were considered local effects, similar to acute gastrointestinal effects reported in human studies. No treatment-related developmental effects were observed below the maternally toxic doses. Treatment-related visceral abnormalities or skeletal malformations were not observed at any dose level. The incidence of delayed ossification of the skull and pelvis was increased slightly in the high-dose group, and an increased incidence of supernumerary ribs occurred in the mid- and high-dose groups. The skeletal variation findings should be considered secondary to maternal toxicity. Of note, a high incidence of extra ribs was reported for all groups $(64,67,80$, and $87 \%$ incidence at $0,6,9$ and $18 \mathrm{mg} \mathrm{Cu} / \mathrm{kg} \mathrm{BW/day,} \mathrm{respectively),} \mathrm{with} \mathrm{the}$ higher incidence at the two highest doses likely related to maternal toxicity-induced stress. Likewise, delayed skull and pelvic ossification may be a transient state and likely represent a stress response to general maternal toxicity, as has been reported for other skeletal development delays (e.g., delayed ossification, wavy rigs, bent long bones, and bent scapulae) (Carney and Kimmel 2007; Kimmel et al. 2014). The NOAEL for maternal toxicity in this study was $6 \mathrm{mg} \mathrm{Cu} / \mathrm{kg} \mathrm{BW/day}$ with the decreased food consumption and associated decrease in weight gain likely related to the acute gastrointestinal effects of copper from the gavage administration of large, focused, bolus doses of copper.

Several studies in young animals have examined the potential for possible increased susceptibility to liver toxicosis at early life stages because of developing copper regulatory mechanisms (Araya et al. 2005; Bauerly et al. 2005; Fuentealba et al. 2000). Bauerly et al. (2005) administered daily doses of $0,0.01$, and $0.025 \mathrm{mg} \mathrm{Cu} /$ day in a $10 \%$ sucrose solution by oral gavage to suckling Sprague-Dawley rat pups followed by weaning to the same diet received by dams during gestation (supplemented to a $13 \mathrm{mg} \mathrm{Cu} / \mathrm{kg}$ standard diet concentration). Pups from each group were sacrificed on postnatal days 10 and 20 to assess age- and dose-related differences in organ and whole body copper levels and effects on various regulatory proteins and copper transporters. The authors reported reduced absorption with increasing copper dose at both ages. Increased copper exposure did not affect body weight, serum copper levels, or ceruloplasmin levels, although increased copper exposure did increase the liver copper concentration. Older pups absorbed more copper with increased copper supplementation compared with 10-day-old pups, although older rats showed increased adaptive mechanisms as reflected by increased metallothionein with copper dose. Fuentealba et al. (2000) fed doses of $1500 \mathrm{mg} \mathrm{Cu} / \mathrm{kg}$ via the diet to young rats from birth until 16 weeks of age and to adult rats for up to 18 weeks. Young rats accumulated more copper in the liver, showed more severe changes in the liver, and had higher serum enzyme activity when compared with adult rats, indicating that at a dose of $1500 \mathrm{mg} \mathrm{Cu} / \mathrm{kg}$, young rats were more susceptible to copper-induced liver injury.

Araya et al. (2005) fed infant rhesus monkeys formula with $0.6 \mathrm{mg} \mathrm{Cu} / \mathrm{L}$ supplemented with $6 \mathrm{mg} \mathrm{Cu} / \mathrm{L}(6.6 \mathrm{mg} / \mathrm{L}$ total; $N=5$ ) from ages 0 to 5 months. No evidence of clinical toxicity or histological damage of the liver was noted under light microscopy, despite increases in liver copper. Some ultrastructural changes in liver cells (e.g., irregularly shaped nuclei containing condensed chromatin) under electron microscopy were observed after 1 month but were normal at 5 months. Twice as many apoptotic cells were observed at 5 months compared with the control, although the frequency of these cells was low in all animals. Araya et al. (2005) postulated that the ultrastructural changes observed might be early cellular damage; however, a major limitation of this study was the availability of only one liver biopsy result from each of the four control animals at 2 months old.

Two studies evaluating the developmental toxicity of copper in rodents provide limited information. Lecyk (1980) reported decreased litter size, decreased fetal weight, and an increase in skeletal malformations in the fetuses of pregnant C57BL and DBA mice fed diets with $\sim 764$ or $1018 \mathrm{mg} \mathrm{Cu} / \mathrm{kg}$ beginning 1 month before conception and continuing through study termination, although no statistical analysis was conducted. The form of $\mathrm{CuSO}_{4}$ used was not reported, and values are approximated based on $\mathrm{CuSO}_{4} \cdot 5 \mathrm{H}_{2} \mathrm{O}$. No effects were reported in mice fed diets containing $127-509 \mathrm{mg} \mathrm{Cu} / \mathrm{kg}$. ECI (2008) estimated a copper LOAEL dose of $123 \mathrm{mg} \mathrm{Cu} / \mathrm{kg} \mathrm{BW} /$ day associated with the diet concentration of $764 \mathrm{mg} \mathrm{Cu} / \mathrm{kg}$. The study did not report on maternal parameters, so it was not possible to evaluate the potential relationship between developmental effects and maternal toxicity. Haddad et al. (1991) administered 0 or $0.158 \%$ copper acetate (equivalent to $0.05 \mathrm{mg}$ $\mathrm{Cu} / \mathrm{L}$ ) in drinking water to Wistar rats for 7 weeks before mating and during gestation. Treatment was associated with reduced embryonic and fetal growth (decreased yolk sac diameter, crown-rump length, and somite number) and delayed skeletal ossification in multiple locations. Although maternal growth was unaffected, maternal toxicity included histopathological changes in the liver (hepatocyte degeneration, focal necrosis, and inflammatory changes) and kidney (degenerative changes in proximal convoluted tubules) typically associated with copper deposition. This study included only one dose $(82 \mathrm{mg} \mathrm{Cu} / \mathrm{kg} \mathrm{BW} /$ day estimated by WHO 2004) with the developmental effects possibly being secondary to maternal toxicity.

Interactions with zinc may affect whether developmental effects occur in laboratory animal studies (Reinstein et al. 1984). In a factorial design experiment, female 
Sprague-Dawley rats were given combinations of 1, 10, 100 , and $1000 \mathrm{mg} \mathrm{Zn} / \mathrm{kg}$ diet (equivalent to $1.39,13.9$, 139.0, and $1390.0 \mathrm{mg} \mathrm{Zn/kg} \mathrm{BW/day)}{ }^{5}$ and $0.5,5,10$, and $100 \mathrm{mg} \mathrm{Cu} / \mathrm{kg}$ in the diet (equivalent to $0.70,7.0,13.9$, and $139.0 \mathrm{mg} \mathrm{Cu} / \mathrm{kg} \mathrm{BW} /$ day) from the time of mating to birth of offspring. Fetal malformations were only noted for subjects with zinc-deficient diets (1 and $10 \mathrm{mg} \mathrm{Zn/kg} \mathrm{diet,} \mathrm{or}$ 1.39 and $13.9 \mathrm{mg} \mathrm{Zn} / \mathrm{kg} \mathrm{BW} /$ day), and the rate of malformations increased as the copper level increased when given with the zinc-deficient diet. It was determined that zinc has an antagonistic role in the diet when provided with copper (Reinstein et al. 1984).

\section{Neurological Disorders}

Copper is an essential metal that has critical roles in brain development and function. Studies suggest that the dysregulation of copper and related metabolic disorders may also result in neurodegenerative diseases through copperregulated mechanisms. Cellular respiration and free radical defense mechanisms rely on activities of the copperrequiring enzymes, such as cytochrome $\mathrm{C}$ oxidase and $\mathrm{Cu}, \mathrm{Zn}$-dependent superoxide dismutase 1 (SOD1). Though not entirely elucidated, copper appears to play a role in amyotrophic lateral sclerosis caused by increased free radical generation possibly linked to a gain of function in SOD1 (Zheng and Monnot 2012). While oxidative damage related to copper and other metal ions is considered an important aspect of neurodegenerative disorders like Alzheimer disease (AD), the role of copper is controversial. The dysregulation of metals such as copper, iron, and zinc has been implicated in oxidative stress and amyloid plaque formation, two common components in $\mathrm{AD}$ (Cheignon et al. 2018).

The majority of the knowledge related to copper dysregulation in neurodegenerative diseases stems from $\mathrm{AD}$ research for which $\mathrm{AD}$ patients display altered regulation of copper and other metals. Key areas of controversy for copper and AD have been whether: (1) excess or deficient copper exposure causes $\mathrm{AD}$ and associated pathogenesis, or (2) AD causes copper dysregulation and thereby excess or deficient copper states and neurodegeneration. While age and likely high lipid intake are the greatest risk factors for developing the disease, $\mathrm{AD}$ is multifactorial and complex, likely with many genetic and environmental contributing factors, and these issues regarding copper have yet to be resolved (Kardos et al. 2018).

The metal-ion excess hypothesis originated from (1) enriched levels of transition elements $\mathrm{Fe}, \mathrm{Zn}$, and $\mathrm{Cu}$ in

\footnotetext{
5 Average rat BW was $0.195 \mathrm{~kg}$; average ingestion rate of $0.272 \mathrm{~kg}$ feed/day was compiled from all experimental conditions (Reinstein et al. 1984).
}

amyloid plaque deposits (mainly consisting of the amyloid $\beta$ peptide; $A \beta$ ) in AD (Atwood et al. 2018; Dong et al. 2003; Lovell et al. 1998) and (2) reports that synthetic $A \beta$ aggregates into fibrils upon binding of copper ions (Bush et al. 1994). Copper's role in plaque accumulation and neuroinflammation may also be influenced by its accumulation specifically in the brain capillaries (Singh et al. 2013). It has also been reported from in vitro studies with murine macrophage BV2 cells and in a mouse model that copper increases the inflammatory response in the brain, which may affect the impairment of plaque clearance (Kitazawa et al. 2016). In triple transgenic 3xTg-AD mice, chronic copper exposure at $250 \mathrm{mg} / \mathrm{L}\left(85 \mathrm{mg} / \mathrm{kg} \mathrm{BW} /\right.$ day $\left.^{6}\right)$ accelerated not only amyloid pathology but also $\tau$ pathology in the brain (Kitazawa et al. 2009). Another study has shown an increase in amyloid- $\beta$ plaques in the brains of Alzheimer's patients related to a higher generation of radicals when amyloid- $\beta$ sugars are in the presence of copper (FicaContreras et al. 2017).

At the same time, the disturbed bioavailability of copper resulting in deficiency is another feature of AD (Kaden et al. 2011), although the mechanisms and the causal relationships of the reduced copper availability in AD are not well understood (Kessler et al. 2006; Schafer et al. 2007; Klevay 2010; Bost et al. 2016; Bulcke et al. 2017; Li et al. 2017; Bagheri et al. 2018; Kardos et al. 2018). AD-associated alterations in metal-ion (primarily copper) homeostasis were found in all regions of $\mathrm{AD}$ brain tissue $\mathrm{Xu}$ et al. 2017), suggesting a pan-cerebral copper deficiency in AD. Such a widespread brain-Cu deficiency may contribute to the pathogenesis by acting through the loss of enzyme functions in energy utilization and antioxidant defenses $(\mathrm{Xu}$ et al. 2017). Reduced copper bioavailability to the brain may be further enhanced by the accumulation of copper in AD plaques (Zheng and Monnot 2012), lipid rafts (Bagheri et al. 2018), or astrocytes (Kardos et al. 2018). Research suggesting that copper supplementation may be beneficial in AD include animal models either overexpressing amyloid precursor protein (APP) or APP in combination with other genes like presenilins and $\tau$, or APP in APLP knockout mice. In the latter, copper levels were found to be increased in cerebral cortex and liver (White et al. 1999). Overexpression of APP resulted in significantly reduced brain copper levels in three different transgenic lines (Maynard et al. 2002; Bayer et al. 2003; Phinney et al. 2003). In APP23 mice which overexpress $\beta$-APP, supplementation with $65 \mathrm{mg} / \mathrm{L} \mathrm{Cu}(\mathrm{II})$ in drinking water (administered as copper sulfate pentahydrate) increased brain copper levels, restored superoxide dismutase, lowered $\beta$-amyloid peptide

\footnotetext{
$\overline{6}$ Assuming a daily water intake of $0.34 \mathrm{~L} / \mathrm{kg} \mathrm{BW} /$ day in mice, and an average weight of $0.0203 \mathrm{~kg}$ for adult male and female mice (US EPA 1988b).
} 
levels, and reduced premature deaths (Bayer et al. 2003). Toxic-milk (txJ) mice with a mutant ATPase7b transporter favoring elevated $\mathrm{Cu}$ levels when crossed with single transgenic (Tg) CRND8 APP mice, at 6 months of age with $30 \mathrm{mg} \mathrm{Cu} / \mathrm{kg}$ in the brain showed a reduced number of amyloid plaques and diminished plasma $A \beta$ levels compared with homozygous TgCRND8 mice and to TgCRND8 APP controls (Phinney et al. 2003). Encouraged by the animal studies exhibiting a beneficial outcome of copper treatment, oral supplementation with $\mathrm{Cu}(\mathrm{II})$ was investigated in a clinical trial (Kessler et al. 2008). Based on indications of copper deficiency (i.e., lower copper and ceruloplasmin-bound copper levels in plasma of $\mathrm{AD}$ patients with advanced biomarkers of the disease in cerebrospinal fluid; Kessler et al. 2006), Kessler et al. (2008) studied the effect of daily exposure of up to $8 \mathrm{mg} \mathrm{Cu}$ (II) over 12 months in AD patients. Plasma copper levels declined in the placebo group, but stabilized in the $\mathrm{Cu}-$ treatment group. The treatment did not affect zinc or nonceruloplasmin levels, although copper had neither a detrimental nor a beneficial effect on AD.

Conversely, several studies have reported the higher levels of total copper and non-ceruloplasmin-bound copper in the serum of $\mathrm{AD}$ patients compared with controls (Bagheri et al. 2018). Squitti et al. (2018) reported the higher levels of non-ceruloplasmin-bound copper and the similar levels of ceruloplasmin-bound copper in the serum of 385 AD patients compared with 336 healthy controls. Serum levels of non-ceruloplasmin-bound copper of $\mathrm{AD}$ patients were also similar to those of nine Wilson's disease patients, although Wilson's disease patients had lower levels of total copper and ceruloplasmin-bound copper than AD patients. Squitti et al. (2002) and Brewer et al. (2010b) attribute the dysregulation of copper in the brains of $\mathrm{AD}$ patients to an increase in the "labile" or exchangeable pool of copper in peripheral circulation as represented by nonceruloplasmin copper. However, the exact chemical nature of this "labile" pool has remained undefined (Ackerman and Chang 2018). Ceruloplasmin is the main copper carrier in plasma (Harris et al. 1999), although many other proteins such as albumin have high bind affinity and capacity for copper and provide reserve binding capacity to keep extracellular ionic copper low. Albumin-bound copper can be delivered to cells and exchanged with other proteins such as transcuprein or with chelators (Linder et al. 2016), and, as noted in the toxicokinetics section, also contributes copper to ceruloplasmin.

As further hypothesized by Brewer (2010a, 2019), increased divalent copper $(\mathrm{Cu}(\mathrm{II}))$ absorption from drinking water or supplements is thought to contribute to this labile pool because divalent copper is not taken up in the gastrointestinal tract by the Ctr1 transporter at the apical membrane of the gastrointestinal tract epithelia cells and processed by the liver, including binding to ceruloplasmin, but instead is rapidly passively absorbed thereby contributing to the non-ceruloplasmin-bound, "labile" copper that can more freely enter the brain. Nevertheless, as noted in the toxicokinetics section, metalloreductases readily reduce $\mathrm{Cu}(\mathrm{II})$ for transport by $\mathrm{Ctr} 1$ and possibly by a distinct saturable transporter for gastrointestinal uptake of $\mathrm{Cu}$ (II) (Lee et al. 2002), and passive absorption appears to be limited even under conditions that would facilitate rapid absorption (e.g., administration of $\mathrm{Cu}$ (II) in liquid to participants in a fasting state; Hill et al. 1986; see the toxicokinetics section). $\mathrm{Cu}$ (II) also rapidly shifts to $\mathrm{Cu}(\mathrm{I})$ in the absence of oxygen (and vice versa). ${ }^{7}$

Direct evidence in humans consuming excess copper in drinking water do not support the hypothesis that $\mathrm{Cu}(\mathrm{II})$ in water elevates non-ceruloplasmin copper and the more "labile" pool of copper. Adult men and women (48-49 individuals per dose group) drinking $<0.01,2,4$, or $6 \mathrm{mg}$ $\mathrm{Cu} /$ day in water for 2 months showed no differences in levels of non-ceruloplasmin copper or parameters reflecting copper loading including red blood cell copper, monocyte copper, superoxide dismutase, serum glutamic-oxaloacetic transaminase, serum glutamic-pyruvic transaminase, and serum gama-glutamyltransferase (Araya et al. 2003b). Thus, for the drinking water levels examined, no effect on nonceruloplasmin-bound copper or copper status was found. Klevay (2010) has also noted that a higher proportion of non-ceruloplasmin-bound copper in $\mathrm{AD}$ patients may occur as a result of decreased ceruloplasmin levels in blood from copper deficiency.

Vascular factors such as hypertension, hypercholesterolemia, and diabetes as well as the inheritance of the epsilon4 allele of the ApoE gene are risk factors for $\mathrm{AD}$ (Sjögren and Blennow 2005). Thus, interactions of high fat diet and copper on the risk of $\mathrm{AD}$ have been a research interest. An animal model of hypercholesterolemic rabbits showed amyloid-inducing effects at very low levels of copper in drinking water $(0.12 \mathrm{mg} \mathrm{Cu} / \mathrm{L})$ (Sparks 2004), with similar results reported in other susceptible species/ strains (spontaneously hypercholesterolemic rabbits, dogs on a $4 \%$ cholesterol diet, transgenic mice with elevated brain amyloid- $\beta$; Sparks et al. 2006). Surprisingly, these findings were made only when copper sulfate was added to distilled water, and not when tap water was used in combination with high cholesterol feed (Sparks and Schreurs 2003). Potable tap water typically contains at least an amount of $\mathrm{Cu}$ of $0.12 \mathrm{mg} \mathrm{Cu} / \mathrm{L}$ as copper carbonate or copper carbonate hydroxide (Kaden et al. 2011) which suggests that such effects occur only in the absence of other minerals normally present in tap water. In the rabbit model, extremely high dietary cholesterol levels of $1-2 \%$ leads to

\footnotetext{
${ }^{7}$ https://pubchem.ncbi.nlm.nih.gov/compound/cupric_ion
} 
serious liver toxicity (steatosis and fibrosis; Buyssens et al. 1996; Xu et al. 1997; Schreurs 2013), thereby affecting copper regulation and homeostasis. Thus, the relevance of these findings have serious limitations as a model for human exposure to copper in tap water because of the unrealistically high cholesterol levels and likely involvement of liver impairment affecting copper regulation along with the absence of normal constituents in tap water. Measurements of liver effects, copper uptake, organ distribution, and excretion in comparison with normal diets versus high cholesterol in feed, would enable a better assessment of potential links between hypercholesterolemia and the risk to develop an Alzheimer-like pathology.

A prospective cohort study of 602 older individuals reported that copper supplements in conjunction with a high saturated and trans-fat diet was associated with cognitive decline (Morris et al. 2006). No effect was found for a high cholesterol diet, and AD was not examined. As cautioned by the authors, the multiple comparisons and potential effects of uncontrolled factors (and chance findings), limit causal conclusions. A randomized controlled trial would provide more clarity of the role of copper supplements. No follow up on the role of copper supplements on $A D$ or cognitive decline has been published in the various large prospective cohort aging studies, although these studies have examined many other dietary nutrients (e.g., Harris 2012). In the Iowa Women's Health Study, Musuru et al. (2011) reported an increased risk of total mortality in older women who took multivitamins, vitamin B6, folic acid, iron, magnesium, or copper, and a decreased risk for calcium. However, unlike for iron and calcium, associations for copper and risk of mortality were only statistically significant at the first follow up and not at the second and third, and no dose-response for copper and risk of mortality was found.

Similar to the use of copper supplementation to treat AD-related copper deficiency, copper chelation therapy has been proposed for $\mathrm{AD}$ based on theories of the effects of a labile pool of excess copper causing $\mathrm{AD}$ and the higher levels of serum levels of copper in AD patients in some studies. However, studies that investigated the role of APP and related APLPs in copper homeostasis strictly contradicted a proposed metal chelation based on a better understanding on the molecular level. Compounds like clioquinol, believed to deplete copper levels in the body (Cherny et al. 2001), were shown to drastically increase the intracellular copper concentration in cells (Treiber et al. 2004). Not surprisingly, Drew (2017) concluded that copper ion chelation therapy has not been effective and should be abandoned. Nevertheless, Squitti et al. (2017) commented that such therapies have not been fully tested and that a portion of $\mathrm{AD}$ patients may benefit. Copper chelator compounds may instead act therapeutically by changing the distribution of copper or facilitating copper uptake (Treiber et al. 2004).

Iron also plays a role in copper regulation in the brain (Monnot et al. 2011). For example, iron deficiency leads to greater copper transport across the blood-brain barrier and promotes copper overload in the central nervous system, though the blood-cerebrospinal fluid barrier is also able to remove excess copper from the cerebrospinal fluid (Monnot et al. 2011). Iron deficiency led to a $70 \%$ increase in cellular copper retention and was mediated by multiple transporters and enzymes (Ctr1, DMT1, ATOX1, and ATP7A) (Monnot et al. 2012). Some of the neurological effects could thus be related to interaction and imbalance associated with other essential elements such as iron (Bandmann et al. 2015).

Copper has also been connected to Parkinson's disease, Huntington's disease, and autism spectrum disorder (ASD), although these links are controversial and not well understood. Copper may play a role in the pathogenesis, or copper deficiency may be an indicator of those at risk for Parkinson's (Bulcke et al. 2017). Copper accumulation in brains of Huntington's disease patients has been implicated in accelerating disease progression; copper chelators and a reduction in copper in the diet was shown to delay the disease progression in animal models (Bulcke et al. 2017). There is some evidence of an association of copper and ASD. Copper levels in plasma of individuals with some forms of ASD were significantly higher than neurotypical individuals and therapy with zinc and B6 reduced copper plasma levels and some ASD symptoms (Russo and deVito 2011); however, the cause(s) of ASD is (or are) currently unknown but thought to be linked to both genetic and environmental factors.

Although copper homeostasis in the brain may be altered at various neurological disease conditions, the available experimental studies in healthy human subjects does not support the view of copper dysregulation due to environmentally relevant exposures to copper. Whether copper exposure affects the risk of $\mathrm{AD}$, under what conditions, and at what levels in susceptible individuals has yet to be established. In general, it appears that copper at environmentally relevant exposures would be well handled by the large majority of the population.

\section{Carcinogenicity and Mutagenicity}

There is no indication that copper is carcinogenic (ECI 2008). Though copper is not considered to be a carcinogen, copper may be a tumor promoter through the modulation of oxidative phosphorylation (Ishida et al. 2013).

Most mutagenicity studies have focused on $\mathrm{CuSO}_{4}$ or the effects of copper ions in relation to DNA damage. Currently, copper is classified as having no mutagenic effects 
(ECI 2008). ECI (2008) reviewed 19 studies from 1975 to 1997 that included cell and animal models. In vitro tests suggest that copper mutagenicity occurs at high, often cytotoxic doses; however, these conditions do not represent normal physiological conditions. The in vitro and in vivo mutagenicity studies are summarized in Supplementary Table S3.

Unlike conditions of in vitro tests, in vivo research indicates that free copper concentrations in the body are low, with the majority of copper bound to albumin or ceruloplasmin (ECI 2008). Inside of cells, it is estimated that less than one copper atom per cell is found as free copper (ECI 2008). Metal binding proteins, such as metallochaperones and antioxidants, occur at high concentrations inside and outside of cells and protect against effects from free ionic copper and other metals or reactive oxygen species (ECI 2008). The majority of these studies also indicate that $\mathrm{CuSO}_{4}$ does not cause mutagenicity in vivo (ECI 2008). Overall, high doses of $\mathrm{CuSO}_{4}$ are cytotoxic, but under normal physiological conditions with the ample presence of copper-binding proteins and low ionic copper, copperinduced oxidative damage to DNA is unlikely to occur.

\section{Dose Response}

\section{Identification of Key Toxicity Endpoints and Populations of Concern}

The key health effects for oral copper exposure are gastrointestinal irritation with acute or short-term exposure, as documented in several well-conducted human studies that have been published since the original study that forms the basis of EPA's action level for copper in drinking water. Acute and repeated-dose studies of ingestion of copper in drinking water at $6 \mathrm{mg} \mathrm{Cu} / \mathrm{L}$ in adults $(0.14 \mathrm{mg} \mathrm{Cu} / \mathrm{kg} \mathrm{BW} /$ day) indicate that a subset of the general population may have gastrointestinal effects such as nausea, though no signs of copper imbalance or liver effects were noted (Pizarro et al. 1999, 2001; Araya et al. 2001, 2003a, 2003b; Uauy et al. 2008; see also Supplementary Tables S2 and S4).

Liver toxicosis from excess copper accumulation with repeated exposure is a potential concern particularly in the first year of life as biliary excretion of copper is developing at a time of potential for high intake per body weight of water used to make formula. Liver toxicosis in populations exposed to elevated copper in drinking water, however, is rare and appears to involve relatively uncommon genetic susceptibility to elevated copper exposure because of dysregulation of copper.

Elevated exposures in the cases of ICC or Tyrolean infantile cirrhosis had water or milk concentrations typically in excess of $5 \mathrm{mg} \mathrm{Cu} / \mathrm{L}$ (O’Neill and Tanner 1989; Müller et al. 1996; Scheinberg and Sternlieb 1994). Not all children were affected in these populations. An experimental study of 3-12-month-old infants consuming formula made with water containing $2 \mathrm{mg} \mathrm{Cu} / \mathrm{L}$ reported increased ceruloplasmin activity at 9 months of age but no other effects on gastrointestinal symptoms, biochemical parameters, liver function indicators, or growth/morbidity (Olivares et al. 1998). No effects other than possible early signs of liver cell damage which were reversible were noted in monkeys administered formula made with water containing $6.6 \mathrm{mg}$ $\mathrm{Cu} / \mathrm{L}$ from birth to 5 months of age (Araya et al. 2005). ${ }^{8}$

Acute gastrointestinal effects thus appear to occur at lower exposure levels (LOAEL $6 \mathrm{mg} \mathrm{Cu} / \mathrm{L}$ ) to copper in drinking water than systemic effects such as liver toxicosis (8.5-8.8 mg Cu/L; Scheinberg and Sternlieb 1994) that have been associated with copper exposure. Although a one-time exposure is sufficient to trigger a gastrointestinal reaction, use of the lower NOAEL drinking water concentration for increased frequency of nausea to calculate a daily dose is also protective of individuals with susceptibility for copper imbalance with higher copper exposures. At a NOAEL of 2-4 mg Cu/L (Araya et al. 2003a; Olivares et al. 1998) for acute gastrointestinal effects, the corresponding dose is $0.06-0.1 \mathrm{mg} \mathrm{Cu} / \mathrm{kg} /$ day, assuming consumption of $2 \mathrm{~L} /$ day of water and a $70 \mathrm{~kg}$ body weight, ${ }^{9}$ or $0.2-0.4 \mathrm{mg} \mathrm{Cu} / \mathrm{kg} /$ day for young child consuming $1 \mathrm{~L} /$ day at a $10 \mathrm{~kg}$ body weight. These doses are in addition to background dietary copper in diet and formula in the repeated-dose studies.

Animal studies indicate a higher NOAEL of $16-17 \mathrm{mg}$ $\mathrm{Cu} / \mathrm{kg} /$ day in the more sensitive animal species, rats, for forestomach lesions, weight reduction, and liver effects (13week feeding study; Hébert 1993). Animal studies investigating reproductive and developmental effects of copper indicate effects to offspring occur at doses that also cause maternal toxicity (typically weight reduction); thus, traditional reproduction and development effects are not sensitive endpoints for copper.

\section{Limitations of Deriving an EPA Reference Dose}

EPA typically develops an oral RfD by identifying a NOAEL dose or, in absence of a NOAEL, a LOAEL based on experimental or epidemiological studies. To account for uncertainty, additional factors are applied to lower the NOAEL or LOAEL value in deriving an RfD. An example is the application of a factor of 10 when extrapolating from

\footnotetext{
${ }^{8}$ Insufficient information was provided to calculate body weightnormalized, daily exposures.

${ }^{9}$ From 0.048 to $0.095 \mathrm{mg} / \mathrm{kg} / \mathrm{day}$ assuming the mean water intake (1.5 L/day) reported in Araya et al. (2003b) and an average body weight from data reported for participants in the control and $6 \mathrm{mg} / \mathrm{L}$ dose groups $(63 \mathrm{~kg})$.
} 
Table 2 US and European oral dietary reference values for copper

\begin{tabular}{|c|c|c|c|c|c|c|}
\hline Group & Age & $\begin{array}{l}\text { Recommended oral } \\
\text { dietary intake } \\
(\mathrm{mg} \mathrm{Cu} / \text { day })\end{array}$ & $\begin{array}{l}\text { Tolerable upper } \\
\text { intake level } \\
(\mathrm{mg} \mathrm{Cu} / \text { day })\end{array}$ & $\begin{array}{l}\text { Recommended oral } \\
\text { dietary intake } \\
(\mathrm{mg} \mathrm{Cu} / \mathrm{kg} \mathrm{BW} / \text { day })\end{array}$ & $\begin{array}{l}\text { Body } \\
\text { weight }(\mathrm{kg})\end{array}$ & Reference \\
\hline Infant & $0-12$ months & $0.20-0.22$ & ND & $0.020-0.022$ & 10 & IOM (2001) \\
\hline Infant & 7-11 months & 0.4 & ND & 0.04 & 10 & EFSA (2015) \\
\hline Children & $1-8$ years & $0.34-0.44$ & $1-3$ & $0.034-0.044$ & 10 & IOM (2001) \\
\hline Children & $9-13$ years & 0.70 & 5 & 0.02 & 37.5 & IOM (2001) \\
\hline Children & 1 to $<3$ years & 0.7 & ND & 0.07 & 10 & EFSA (2015) \\
\hline Children & 3 to $<10$ years & 1 & ND & 0.01 & 10 & EFSA (2015) \\
\hline Boys, girls & 10 to $<18$ years & $1.3,1.1$ & ND & 0.02 & 53.9 & EFSA (2015) \\
\hline Adolescents & $14-18$ years & 0.89 & 8 & 0.02 & 53.9 & IOM (2001) \\
\hline Adults, both genders & $19-70+$ years & 0.90 & 10 & 0.013 & 70 & IOM (2001) \\
\hline Men, women & NA & $1.6,1.3$ & ND & 0.02 & 70 & EFSA (2015) \\
\hline $\begin{array}{l}\text { Women, pregnant, } \\
\text { lactating }\end{array}$ & $14-50$ years & $1.0,1.3$ & $8-10$ & $0.014,0.019$ & 70 & IOM (2001) \\
\hline $\begin{array}{l}\text { Adult, pregnant and } \\
\text { lactating women }\end{array}$ & NA & 1.5 & ND & 0.02 & 70 & EFSA (2015) \\
\hline
\end{tabular}

Weights used to calculate recommended oral dietary intake (mg Cu/kg BW/day) from US EPA 1997

$N D$ not determined

studies in animal to humans (US EPA 1993). After incorporating default uncertainty factors of 10 each for animalto-human extrapolation, variability within humans, and subchronic to chronic exposure extrapolation, oral RfDs calculated based on the available data for repeated-dose copper toxicity in animals are within dietary levels. For example, the NOAEL value from the best available animal studies (Hébert et al. 1993; Hébert 1993) would, after application of default uncertainty factors (UFs; e.g., 1000) (Supplementary Table S4; US EPA 1993), result in an RfD similar to the recommended dietary allowance for copper $(0.9 \mathrm{mg} \mathrm{Cu} /$ day for adults or $0.013 \mathrm{mg} \mathrm{Cu} / \mathrm{kg} / \mathrm{day}$; IOM 2004; Table 2). Use of the NOAEL from the human studies (e.g., 0.06-0.1 mg Cu/kg/day) with default UFs for within human variation or subchronic to chronic extrapolation (100) would result in RfDs of 0.0006-0.001 mg Cu/ $\mathrm{kg} /$ day, orders of magnitude below the recommended dietary allowance.

RfDs are intended to be protective of toxicity caused by excess exposure and are typically not below doses deemed essential and therefore well-tolerated (US EPA 2007). The complexity in determining an RfD for essential nutrients is that adverse effects are associated with both excess and deficient exposures. For essential metals, a tolerable upper intake level, which is the highest amount of a daily metal nutrient that can be consumed without adverse effects to the majority of the population, can also be developed, as reported by IOM (2001) for copper (Table 3). On the other hand, an upper tolerance level for a nutrient may not be protective for sensitive populations. Upper tolerance limits for copper are more applicable to dietary intake than for fluid intake, which is the medium that has been associated with the most common effects of copper (acute gastrointestinal effects) in humans. The upper tolerance limit recommended by IOM (2001) relied upon studies by Pratt et al. (1985) and O'Donohue et al. (1993) that determined a NOAEL of $10 \mathrm{mg} \mathrm{Cu}$ /day (Pratt et al. 1985). In Pratt et al. (1985), subjects received $10 \mathrm{mg}$ of $\mathrm{Cu} /$ day as copper gluconate or a placebo for 12 weeks. Subjects in the two groups showed no statistical difference between the incidence of nausea, diarrhea, and heartburn. No changes were observed in biochemical analyses or in copper levels in serum, urine, or hair, and no liver damage occurred. In O'Donohue et al. (1993), a case study describes one adult male consuming $30 \mathrm{mg} \mathrm{Cu} /$ day via copper supplements for 2 years, followed by $60 \mathrm{mg} \mathrm{Cu}$ /day for an additional and unspecified amount of time (IOM 2001; O'Donohue et al. 1993). The patient required a liver transplant. Current international regulatory guidelines and recommendations for copper ingestion are found in Table 3.

A different approach than the EPA RfD methodology, the categorical regression analysis, also recognizes copper essentiality in deriving a health-protective oral dose. Copper essentiality results in a U-shaped exposure-response relationship caused by both adverse effects at high and low doses. Categorical regression is a method that can integrate information from many types of copper deficiency and toxicity studies with variations in study design, dose concentration, or study organisms in developing an exposureresponse curve by simultaneous modeling of both deficiency and excess toxicity dose-response relationships (Chambers et al. 2010; Krewski et al. 2010a, 2010b; Milton 


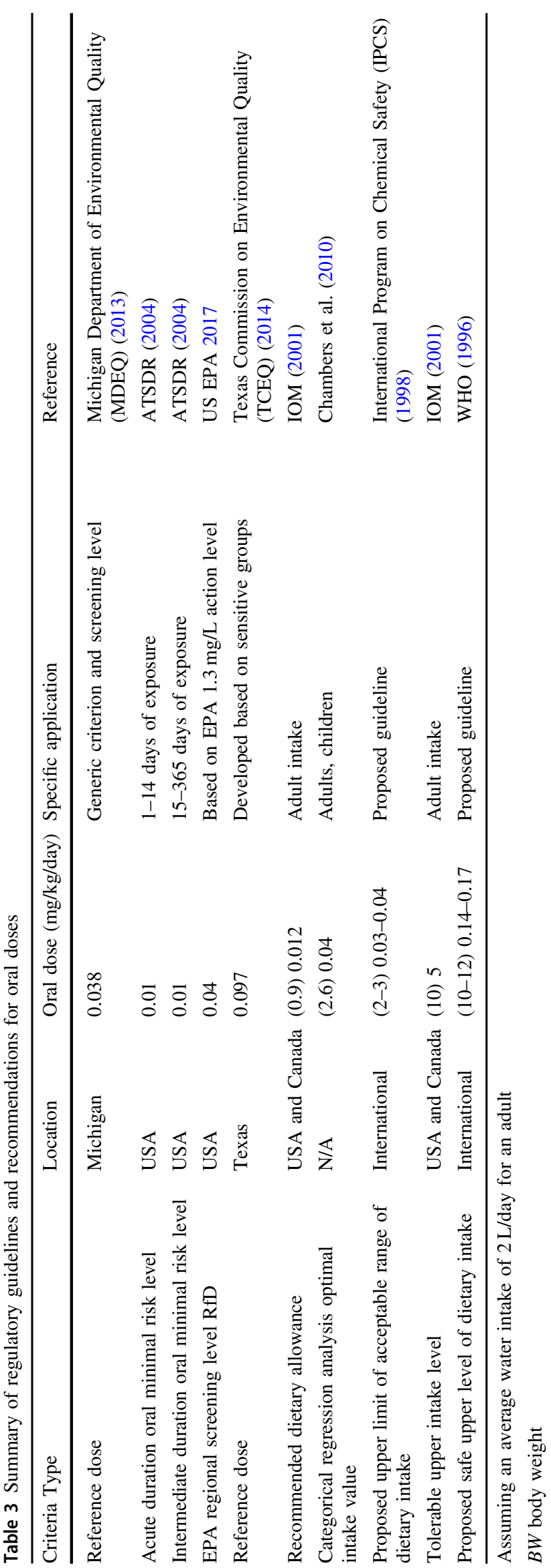

et al. 2017a). This approach has also been considered for another essential metal, manganese (Milton et al. 2017b).

The copper exposure-response data considered in the categorical regression analysis were from studies in humans or animals exposed to copper from food or water. These studies were selected using inclusion/exclusion criteria based on data quality and usefulness in an exposure assessment (Chambers et al. 2010). A total of 207 exposureresponse data points were used for the copper excess category, and 208 data points were used in the copper deficiency category (Chambers et al. 2010). To harmonize the magnitude and types of health effects associated with data on doses from different studies, health effects for each data point were ranked in "severity" and associated with a dose and duration of exposure (Chambers et al. 2010). The categorical regression models rank the response based on varying categories of severity, rather than along a continuous or linear scale. Seven categories of severity were used for the copper data, including 0) no effect (NOAEL); (1) biological effects within the homeostatic range; (2) early signs of copper imbalance; (3) perturbations in copper metabolism; (4) gross reversible toxicity; (5) gross irreversible toxicity with some examples including mortality, reproductive effects, and changes to organ weight; and (6) death (Chambers et al. 2010). In addition, this analysis can be used to predict the probability of different severity levels based on one or more independent variables selected (e.g., dose, duration). The analysis is also able to incorporate variation in human studies and animal models, such as species, sex, age, and study design (Krewski et al. 2010b). Modeling was conducted using the CatReg software developed by US EPA (2000).

Modeling of a single U-shaped dose-response curve to predict a dose that minimized the risk of adverse effects from excess and deficiency identified an optimal intake level of $0.039 \mathrm{mg} \mathrm{Cu} / \mathrm{kg} \mathrm{BW} /$ day or $2.73 \mathrm{mg} \mathrm{Cu} /$ day at a $70 \mathrm{~kg}$ body weight (Milton et al. 2017a). This dose was based on exposure-response models for excess and deficiency defined at a severity rank of 2 (possible early signs of copper accumulation/deficiency) (Chambers et al. 2010).

\section{Discussion}

\section{Summary of Current Copper Toxicity Knowledge}

The available literature on copper continues to indicate that the most sensitive adverse effect of increased oral exposures in the general population is irritation of the gastrointestinal tract, causing acute nausea. Copper is not reported to be carcinogenic or mutagenic, nor are reproductive or in utero effects sensitive endpoints. Sensitivity to systemic copper toxicity to the liver, kidneys, or central nervous system with 
repeated exposure appears to be related to genetically based disorders in copper regulation. Known regulatory disorders resulting in copper accumulation and toxicity (e.g., Wilson's diseases or other rare autosomal conditions) result in serious health consequences at normal exposure levels associated with nutritional requirements and thus cannot be managed with regulatory limits. Infants in the first year of life could be more susceptible to copper overload because of their developing copper excretion capabilities. Reduced excretory capability is in part balanced by nutritional requirements in this rapidly developing life stage; however, formula-fed infants may be more susceptible to liver toxicity at elevated copper exposures in drinking water. Nevertheless, elevated copper exposures in formula-fed infants in population-based (Scheinberg and Sternlieb 1994; Zietz et al. 2003) or experimental (Olivares et al. 1998; Araya et al. 2005) studies have not reported clear evidence of copper imbalance or liver toxicosis at drinking water levels of $2 \mathrm{mg} \mathrm{Cu} / \mathrm{L}$ to $2-4$ times higher. The relatively few isolated case studies of liver toxicosis in children therefore suggests the importance of genetic susceptibility to increased copper exposure.

\section{Evaluation of the Optimal Intake Level for Copper as an RfD}

Compared with the recommended oral copper intake values used by IOM and the European Food Safety Authority described in Table 2 and additional recommended daily intake values in Table 4, the categorical regression-derived optimal intake value $(0.04 \mathrm{mg} \mathrm{Cu} / \mathrm{kg} \mathrm{BW} /$ day $)$ is $2-3$ times higher than recommended oral dietary intakes for adults, similar to the acceptable upper limit proposed by the International Program on Chemical Safety (IPCS 1998), and is approximately two orders of magnitude lower than tolerable and safe upper dietary levels proposed by WHO, IOM, and Health Canada (Table 4). No studies published since the development of the 2010 evaluations of a categorical regression optimal level provide relevant toxicity information that affects this value.

The $2.7 \mathrm{mg} \mathrm{Cu} /$ day optimal dose (assuming a 70-kg body weight used by Milton et al. 2017) is also lower than the $6 \mathrm{mg} \mathrm{Cu}$ /day LOAEL for gastrointestinal effects and nausea for copper in drinking water observed in the human experimental trials, and the $4 \mathrm{mg} \mathrm{Cu}$ /day NOAEL for gastrointestinal effects and nausea after 2 months of exposure (Araya et al. 2003a, 2003b). Exposure to copper in drinking water in this study was in addition to $0.9 \mathrm{mg} \mathrm{Cu} /$ day estimated from the diet (Araya et al. 2003b). Thus, the optimal dose as an RfD appears to have sufficient margin of exposure to allow for additional background dietary intake. Ingestion of copper from the diet plus supplements may add $2 \mathrm{mg} / \mathrm{day}$ (IOM 2001) or about $0.03 \mathrm{mg} \mathrm{Cu} / \mathrm{kg} \mathrm{BW/day.}$ However, diet and multivitamin supplements would also

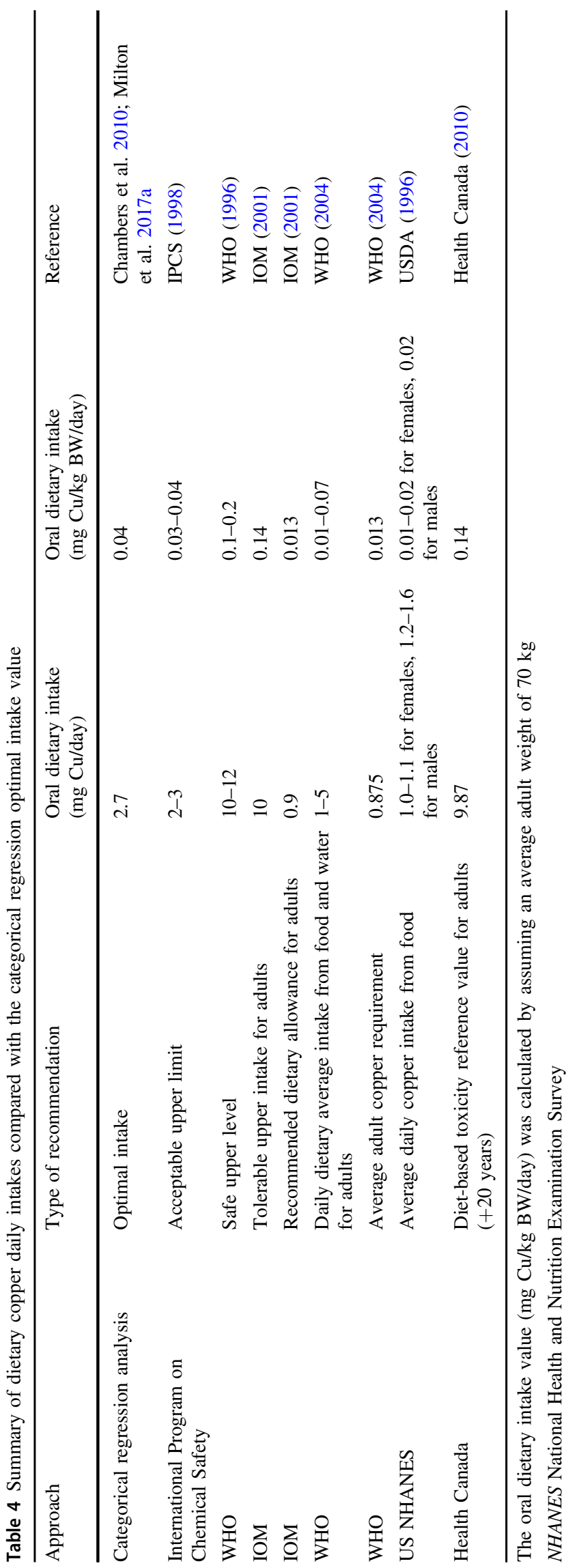


contain other minerals such as zinc and iron that reduce copper absorption and toxicity (ATSDR 2004). The RfD is not intended to be protective of individuals with excessive ingestion of copper supplements, as demonstrated by an extreme case of liver failure resulting from consumption of a tablet with $30 \mathrm{mg} \mathrm{Cu} /$ day for 2 years followed by $60 \mathrm{mg}$ $\mathrm{Cu} /$ day for an unknown additional duration (O'Donohue et al. 1993).

For children, the $0.04 \mathrm{mg} \mathrm{Cu} / \mathrm{kg} \mathrm{BW} /$ day optimal dose would be associated with a water or milk concentration for a $10-\mathrm{kg}$ young child drinking $1 \mathrm{~L} /$ day of $0.4 \mathrm{mg} \mathrm{Cu} / \mathrm{L}$. This concentration is below the $1.3 \mathrm{mg} \mathrm{Cu} / \mathrm{L}$ recommended by NRC (2000) for the protection of infants with genetic susceptibility to increased environmental copper exposure, the $2 \mathrm{mg} / \mathrm{L}$ that was a NOAEL for formula-fed infants (Olivares et al. 1998), and the copper milk concentrations associated with ICC and Tyrolean infantile cirrhosis (O'Neill and Tanner 1989; Müller et al. 1996). Similar to the studies in adults, the infants in the experimental study by Olivares et al. (1998) were also exposed to background levels of copper in formula in addition to that added from the use of drinking water to make the formula.

The optimal level (rounded to $0.04 \mathrm{mg} \mathrm{Cu} / \mathrm{kg} / \mathrm{BW} / \mathrm{day}$ ) based on the categorical regression is equivalent to exposure from chronic consumption (i.e., $2 \mathrm{~L} /$ day at a lifetime average body weight of $70 \mathrm{~kg}$ ) of drinking water containing copper at EPA's action level of $1.3 \mathrm{mg} \mathrm{Cu} / \mathrm{L}$. Accordingly, this dose ( $0.04 \mathrm{mg} \mathrm{Cu} / \mathrm{kg} / \mathrm{BW} /$ day) is also consistent with the RfD for copper (calculated from the drinking water action level) that is used in EPA's screening level for soil and tap water (US EPA 2017). Thus, although the current literature on copper is insufficient to establish chronic toxicity levels for genetically susceptible individuals, the optimal level is also consistent with the findings of the NRC (2000) that $1.3 \mathrm{mg}$ $\mathrm{Cu} / \mathrm{L}$ would be protective of individuals who might be susceptible to copper metabolism disorders at higher copper concentrations. The categorical regression analysis included studies with values taken from food and water ingestion, though it is unknown whether the categorical regression analysis included copper supplement studies.

The Agency for Toxic Substances and Disease Registry (ATSDR) intermediate minimal risk level of $0.01 \mathrm{mg} / \mathrm{kg} /$ day for copper (ATSDR 2004) was based on the 2-month experimental drinking water study of Araya et al. (2003b). ATSDR, however, disagreed with the statistical tests (i.e., use of the Bonferroni multiple comparisons correction) in this study and selected a lower LOAEL at $4 \mathrm{mg} \mathrm{Cu} / \mathrm{L}$ and NOAEL at $2 \mathrm{mg} \mathrm{Cu} / \mathrm{L}$. Based on the reported dose per body weight in a subset of volunteers, the corresponding dose at the NOAEL was $0.045 \mathrm{mg} / \mathrm{kg} / \mathrm{day}$. ATSDR divided by a UF of 3 for human variability, resulting in the minimal risk level of $0.01 \mathrm{mg} / \mathrm{kg} /$ day. This additional UF seems unnecessary given the large number of study subjects (327-355 per exposure group for gastrointestinal effects; 48-49 per group for clinical parameters), the direct nature of the effect (i.e., irritation should be less variable than for effects involving chemical metabolism, for example), the mild increase in frequency of gastrointestinal symptoms at the LOAEL (difference of $3 \%$ between 2 and $4 \mathrm{mg} / \mathrm{L}$ for the fraction reporting one or more symptoms over the 2-month period), and consistent findings of no effects at $2 \mathrm{mg} / \mathrm{L}$ and higher in several other controlled experimental human studies in other populations.

Comparisons can be made between the recommended daily copper intakes (Table 3 ) and regulations for copper in drinking water (Table 5). The State of Michigan (MDEQ 2015) proposed an oral $\mathrm{RfD}$ of $0.001 \mathrm{mg} \mathrm{Cu} / \mathrm{kg} / \mathrm{day}$ by dividing the ATSDR intermediate minimal risk level by a UF of 10 to extrapolate to longer-term exposure ${ }^{10}$. However, this extrapolation is unnecessary because the sensitive endpoint is gastrointestinal effects, which is a short-term effect, and for systemic effects the most susceptible population would be early life stages when copper regulation is less competent (OEHHA 2008). As noted by NRC (2000), the weight of evidence from the literature indicates rare occurrences of liver toxicosis are associated with genetically susceptible infants and children ingesting copper fluid concentrations well in excess of $1.3 \mathrm{mg} / \mathrm{L}$ (equivalent to $0.13 \mathrm{mg} \mathrm{Cu} / \mathrm{kg} /$ day for 1 liter/day and $10 \mathrm{~kg}$ body weight).

The state of California (OEHHA 2008) has derived a public health goal (PHG) for copper in drinking water of $0.3 \mathrm{mg} \mathrm{Cu} / \mathrm{L}$, based on a NOAEL for gastrointestinal effects in infants of $2 \mathrm{mg} / \mathrm{L}$ from the experimental study of copper in water used to make formula (Olivares et al. 1998). OEHHA (2008) identified an equivalent NOAEL dose of $0.426 \mathrm{mg} \mathrm{Cu} / \mathrm{kg} /$ day from water and formula, based on the highest dose reported for the high-dose infant group (mean intake plus the standard deviation) reported for the first 3 months of exposure. A UF of 3 was applied to the NOAEL to account for study uncertainties, resulting in a dose of $0.142 \mathrm{mg} \mathrm{Cu} / \mathrm{kg} /$ day. To derive a PHG drinking water level, OEHHA applied a relative source contribution of 0.5 and used a 95 th percentile infant water consumption per body weight from national survey data. ${ }^{11}$

The state of Texas developed an oral RfD for copper of $0.097 \mathrm{mg} \mathrm{Cu} / \mathrm{kg} /$ day (TCEQ 2014) also based on Olivares et al. (1998). However, TCEQ used a time-weight average concentration from this study of $0.291 \mathrm{mg} \mathrm{Cu} / \mathrm{kg} /$ day as the NOAEL, and applied a UF of 3 (due to the limited availability of human data) to derive an oral RfD (TCEQ 2014).

\footnotetext{
${ }^{10}$ The proposed RfD was never accepted. The RfD reverted to the earlier value, which is $0.038 \mathrm{mg} / \mathrm{kg} / \mathrm{day}$ (MDEQ 2013), and is similar to the RfD used by EPA to calculate Region Screening Levels for copper.

${ }^{11}[426 \mu \mathrm{g} / \mathrm{kg} \mathrm{BW} / \mathrm{day} \times 0.5] /[3 \times 0.221 \mathrm{~L} / \mathrm{kg}$-day $]=321 \mu \mathrm{g} / \mathrm{L}$ as the public health goal for drinking water.
} 


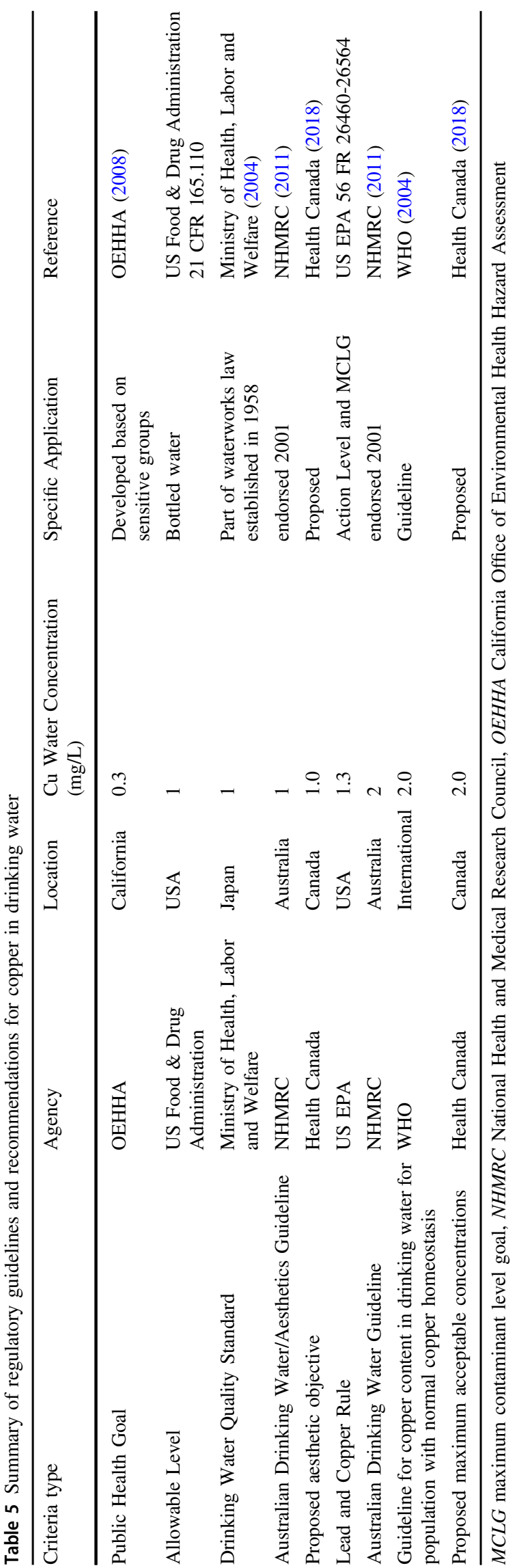

The Federal-Provincial-Territorial Committee on Drinking Water (Health Canada) recently proposed a maximum acceptable concentration for total copper in drinking water of $2.0 \mathrm{mg} \mathrm{Cu} / \mathrm{L}$ (Health Canada 2018). The maximum acceptable concentration is also based on Olivares et al. (1998). A tolerable daily intake for free copper $(0.426 \mathrm{mg}$ $\mathrm{Cu} / \mathrm{kg} /$ day total dose from water and formula) was estimated as protective of gastrointestinal effects and liver function in formula-fed infants. The average body weight of an infant of $7 \mathrm{~kg}$ and tap water consumption rate of $0.75 \mathrm{~L} /$ day for an infant as well as a relative source contribution of 0.5 were applied to the tolerable daily intake resulting in a maximum acceptable concentration of $2.0 \mathrm{mg} \mathrm{Cu} / \mathrm{L}$. ${ }^{12}$ Though Health Canada and OEHHA (2008) use the same NOAEL derived from Olivares et al. (1998), different recommendations are provided by these two agencies due to differences in the estimated daily volume of tap water consumed and a UF.

A copper risk assessment (summarized by Delbeke et al. 2010), initiated by the copper industry with methodologies developed in collaboration with other stakeholders, was reviewed and endorsed by both the EU Technical Committee on New and Existing Substances and the EU Scientific Committee on Health and Environmental Risks (ECI 2008). This assessment derived an internal systemic safe threshold value for workers of $0.041 \mathrm{mg} \mathrm{Cu} / \mathrm{kg} \mathrm{BW} /$ day based on liver effects from animal studies and assuming a human oral absorption range of $30-60 \%$ for copper. The value corresponds to an upper limit of $2.87 \mathrm{mg} \mathrm{Cu}$ /day for ingested copper, assuming a body weight of $70 \mathrm{~kg}$. A safe threshold value for water of $4 \mathrm{mg} \mathrm{Cu} / \mathrm{L}$ was also derived based on acute nausea and gastrointestinal effects in humans. The $2-3 \mathrm{mg} \mathrm{Cu} /$ day is comparable with the proposed upper limit of acceptable range of oral intake proposed by ICPS (1998) and is similar to the $2.7 \mathrm{mg} \mathrm{Cu} /$ day proposed by Milton et al. (2017a) for the general population.

In summary, most of the available criteria are similar or higher than an RfD of $0.04 \mathrm{mg} / \mathrm{kg} / \mathrm{day}$. The few lower criteria (i.e., ATSDR MRL) are related and are lower than necessary because of the use of additional UFs that are not warranted based on the body of evidence.

\section{Uncertainties in the Categorical Regression Analysis and Assessment of an RfD}

Although the CatReg software is recognized as somewhat simplistic, it is still considered the most reliable method for determining a dose-response curve for essential nutrients. Research needed to strengthen the copper model developed

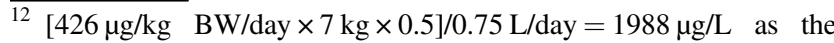
maximum acceptable concentration.
} 
by Krewski et al. (2010a) includes more research in humans, animal models, various life stages, and multiple endpoints, with all experiments using standard designs to better refine the categorical regression analysis technique. Historically, animal studies have focused on severely deficient copper doses, and less information is available on the details of health effects over a wide range of deficient copper concentrations in multiple target organs and other endpoints such as reproductive, cardiovascular, developmental, and immunological effects (Stern 2010). The copper literature shows that more studies on marginal excess or marginal deficiency are needed, as well as a broad range of markers used in the same studies (Krewski et al. 2010a). More information from chronic exposures was also noted as an area of research need (Krewski et al. 2010a), although based on the mode of action for copper, doses that are protective of gastrointestinal effects and that do not disrupt copper homeostasis would also be expected to be protective of long-term exposure. Although more research would help refine the model, the resulting optimal level is generally supported by the overall weight of evidence on toxicity as well as experience on well-tolerated doses within dietary intakes.

Potential limitations of the categorical regression analysis include the use of a relatively small dataset; however, over 400 exposure-response data points were used in the analysis. Another limitation is an uneven distribution of data in the various severity rankings (Chambers et al. 2010). For example, in human drinking water studies, no severity ranks between 1 and 3 were classified, with only severity in 0 (no effect) or 4 (gross reversible toxic effects) observed (Chambers et al. 2010). In other cases, severity categories were combined if no studies were found, e.g., for copper exposure studies, no severity rank of 5 was available, and therefore severity levels 4-6 were combined (Chambers et al. 2010). No deficiency studies were available in any model organism for the severity rank of 5. Running the categorical regression analysis with severity ranks grouped into a total of three categories was also tried as too many severity rank categories may not have been appropriate given the small sample size (Chambers et al. 2010).

The ability to modify the model gives some allowance for data quality or data limitations. In addition, because categorical regression considers multiple exposure media (food versus water), variations in absorption is also indirectly considered; for example, a lower dose in drinking water produced the same effect as a higher dose in food (Chambers et al. 2010). However, more information is needed for understanding the comparison between copper bioavailability in water ingestion and food intake. The available copper dataset also needed some extrapolations: human data among the higher severity ranks were estimated due to a lack of data, and short-term data were used to estimate subchronic exposure-response relationships (Chambers et al. 2010). In addition, a sparseness of data for chronic exposures made characterizing an acceptable and reliable chronic exposure range challenging (Chambers et al. 2010).

Despite its limitations, and though not specifically designed for developing an RfD, the categorical regression analysis provides information on a dose that is likely to be protective of adverse effects from excess exposure without being unreasonably low for an essential and well-tolerated element. Although the available studies and case reports indicate higher levels may also be without gastrointestinal effects or copper imbalance, uncertainties in the levels at which susceptible individuals might have copper accumulation and liver or other organ toxicity indicates caution in raising the RfD. Genetic susceptibility is likely to involve multiple genes, resulting in a dose continuum at which individuals may be susceptible to copper overload. An RfD that is well within customary tolerable levels with a considerable margin of exposure from levels known to result in imbalance in susceptible individuals should be protective of even those with environmental sensitivity. The small fraction of individuals at risk of copper overload within normally tolerated doses would likely require medical care for background exposures.

\section{Conclusions}

Due to the essentiality of copper, assessments of oral doseresponse have remained a challenge, especially given the uncertainties with genetically susceptible populations. The traditional IRIS-based RfD calculation using a NOAEL or LOAEL from animal or human studies with default UFs results in values below the recommended daily intake for copper. Categorical regression analysis provides an optimal dose with the least potential for risk of health effects from both deficiency and toxicity in humans. The resulting dose of $2.7 \mathrm{mg} \mathrm{Cu} / \mathrm{day}$, or $0.04 \mathrm{mg} \mathrm{Cu} / \mathrm{kg} \mathrm{BW} /$ day given a $70-\mathrm{kg}$ lifetime average, could be considered as a chronic RfD, based on the mode of action of copper overload for which homeostatic copper regulation with subchronic exposures should be protective of long-term exposures as well. This dose is also protective of children and those with genetic susceptibility to increased copper intake (above typical levels) based on experimental, observational, or case studies of infants and children exposed to elevated copper in drinking water, formula, or milk. Using the optimal intake value as an $\mathrm{RfD}$ is therefore protective of both adults and children.

Acknowledgements We would like to thank E. Markowsky, J. Sanders, and S. Marzooghi for help with reviewing the manuscript and B. Dowd for creating the graphical abstract. 


\section{Compliance with Ethical Standards}

Conflict of Interest The present review was conducted with funding support from the Copper Development Association and International Copper Association, which were provided an opportunity to review a draft and offer comments for consideration by the authors. The authors have sole responsibility for the content and writing of the review. The interpretations and views expressed are not necessarily those of the sponsors or the authors' employers or clients.

Publisher's note Springer Nature remains neutral with regard to jurisdictional claims in published maps and institutional affiliations.

Open Access This article is distributed under the terms of the Creative Commons Attribution 4.0 International License (http://crea tivecommons.org/licenses/by/4.0/), which permits unrestricted use, distribution, and reproduction in any medium, provided you give appropriate credit to the original author(s) and the source, provide a link to the Creative Commons license, and indicate if changes were made.

\section{References}

Ackerman CM, Chang CJ (2018) Copper signaling in the brain and beyond. J Biol Chem 293(13):4628-4635

Araya M, McGoldrick MC, Klevay LM, Strain JJ, Robson P, Nielsen F, Olivares M, Pizarro F, Johnson L, Poirier KA (2001) Determination of an acute no-observed-adverse-effect level (NOAEL) for copper in water. Regul Toxicol Pharmacol 34:137-145

Araya M, Chen B, Klevay LM, Strain JJ, Johnson L, Robson P, Shi W, Nielsen F, Zhu H, Olivares M, Pizarro F, Haber LT (2003a) Confirmation of an acute no-observed-adverse-effect level (NOAEL) and low-observed-adverse-effect level (LOAEL) for copper in bottled drinking water in a multi-site international study. Regul Toxicol Pharmacol 38:389-399

Araya M, Olivares M, Pizarro F, González M, Speisky H, Uauy R (2003b) Gastrointestinal symptoms and blood indicators of copper load in apparently healthy adults undergoing controlled copper exposure. Am J Clin Nutr 77(3):646-650

Araya M, Kelleher SL, Arredondo MA, Sierralta W, Vial MT, Uauy R, Lönnerdal B (2005) Effects of chronic copper exposure during early life in rhesus monkeys. Am J Clin Nutr 81(5):1065-1071

Aschengrau A, Zierler S, Cohen A (1989) Quality of community drinking water and the occurrence of spontaneous abortion. Environ Health 44(5):283-290

Aschengrau A, Zierler S, Cohen A (1993) Quality of community drinking water and the occurrence of late adverse pregnancy outcomes. Environ Health 48(2):105-113

Agency for Toxic Substances and Disease Registry (ATSDR) (2004) Toxicological profile for copper. ATSDR. Atlanta, Georgia. https://www.atsdr.cdc.gov/toxprofiles/tp132.pdf

Atwood CS, Huang X, Moir RD, Tanzi RE, Bush AI (2018) Role of free radicals and metals ions in the pathogenesis of Alzheimer's disease. In Metal ions in biological systems. Routledge, New York, p 209-364

Bagheri S, Squitti R, Haertlé T, Siotto M, Saboury AA (2018) Role of copper in the onset of Alzheimer's disease compared to other metals. Front Aging Neuroscience 9:446

Bandmann O, Weiss KH, Kaler SG (2015) Wilson's disease and other neurological copper disorders. Lancet Neurol 14(1):103-113

Bauerly KA, Kelleher SL, Lonnerdal B (2005) Effects of copper supplementation on copper absorption, tissue distribution, and copper transporter expression in an infant rat model. Am J Physiol Gastrointest Liver Physiol 288(5):G1007-G1014
Bayer TA, Schäfer S, Simons A, Kemmling A, Kamer T, Tepests R, Eckert A, Schüssel K, Eikenberg O, Sturchler-Pierrat C, Abramowski D (2003) Dietary $\mathrm{Cu}$ stabilizes brain superoxide dismutase 1 activity and reduces amyloid A $\beta$ production in APP23 transgenic mice. PNAS 100(24):14187-14192

Beinhardt S, Leiss W, Stattermayer AF, Graziadei I, Zoller H, Stauber R, Maieron A, Datz C, Steindl-Munda P, Hofer H, Vogel W, Trauner M, Ferenci P (2014) Long-term outcomes of patients with Wilson disease in a large Austrian cohort. Clin Gastroeneterol Hetapol 12:683-689

Bost M, Houdart S, Oberli M, Kalonji E, Huneau JF, Margaritis I (2016) Dietary copper and human health: current evidence and unresolved issues. J Trace Elem Med Biol 35:107-115

Brewer GJ, Yuzbasiyan-Gurkan V, Dick R, Wang Y, Johnson V (1993) Does a vegetarian diet control Wilson's disease? J Am Coll Nutr 12(5):527-530

Brewer GJ (2000) Is heterozygosity for a Wilson's disease gene defect an important underlying cause of infantile and childhood copper toxicosis syndromes? J Trace Elem Exp Med 13:249-254

Brewer GJ (2010a) Letter to the editor: toxicity of copper in drinking water. J Toxicol Environ Health Part B 13:449-459

Brewer GJ, Kanzer SH, Zimmerman EA, Celmins DF, Heckman SM, Dick R (2010b) Copper and ceruloplasmin abnormalities in Alzheimer's disease. Am J Alzheimer's Dis Other Dement 25 (6):490-497

Brewer GJ (2019) The scourge of our time, Alzheimer's disease, can be prevented by two simple steps. Acta Sci Nutritional Health 3.2:54-60

Bulcke F, Dringen R, Scheiber IF (2017) Neurotoxicity of Copper. In: Aschner M, Costa LG (eds) Neurotoxicity of metals. Springer International Publishing, Cham, p 313-343

Bush AI, Pettingell WH, Multhaup G, Paradis MD, Vonsattel JP, Gusella JF, Beyreuther K, Masters CL, Tanzi RE (1994) Rapid induction of Alzheimer A beta amyloid formation by zinc. Science 265(5177):1464-1467

Buyssens N, Kocky MM, Herman AG, Lazou JM, Van Den Berg K, Wisse E, Geerts A (1996) Centrolobular liver fibrosis in the hypercholesterolemic rabbit. Hepatology 24(4):939-946

Cabrera-Muñoz MDL, Marrufo JDG, Pantaleón OM, Santos PB (2010) Idiopathic copper toxicosis in an infant. Bol Med Hosp Infant Mex 67:359-368

Carney EW, Kimmel CA (2007) Interpretation of skeletal variations for human risk assessment: delayed ossification and wavy ribs. Birth Defects Res Part B 80(6):473-496

Copper Development Association, Inc. (CDA) (2016) Who is choosing copper now? https://www.copper.org/applications/plumbing/ water_service/resources/A4118_Service_Line_WhoIsChoosing Fact_Sheet.pdf. Accessed 1 Feb 2019

CDA. Personal communication. Percent of copper used in newly constructed households

Ceko MJ, Aitken JB, Harris HH (2014) Speciation of copper in a range of food types by $\mathrm{x}$-ray absorption spectroscopy. Food Chem 164:50-54

Chambers A, Krewski D, Birkett N, Plunkett L, Hertzberg R, Danzeisen R, Aggett PJ, Starr TB, Baker S, Dourson M, Jones P, Keen CL, Meek B, Schoeny R, Slob W (2010) An exposureresponse curve for copper excess and deficiency. J Toxicol Environ Health, Part B 13(7-8):546-578

Cheignon C, Tomas M, Bonnefont-Rousselot D, Faller P, Hureau C, Collin F (2018) Oxidative stress and the amyloid beta peptide in Alzheimer's disease. Redox Biology 14:450-464

Cherny RA, Atwood CS, Xilinas ME, Gray DN, Jones WD, McLean CA, Barnham KJ, Volitakis I, Fraser FW, Kim YS, Huang X (2001) Treatment with a Copper-Zinc chelator markedly and rapidly inhibits $\beta$-amyloid accumulation in Alzheimer's disease transgenic mice. Neuron 30(3):665-676 
Danks DM (1995) Disorders of copper transport. In: Scriver CR, Beaudet AL, Sly WM, Valle D (eds) The metabolic and molecular basis of inherited disease. McGraw-Hill, New York, p 2211-2235

Das SK, Ray K (2006) Wilson's disease: an update. Nat Clin Pract Neurol 2:482-493

De Bie P, Muller P, Wijmenga C, Klomp LWJ (2007) Molecular pathogenesis of Wilson and Menkes disease: correlation of mutations with molecular defects and disease phenotypes. J Med Genet 44(11):673-688

Delbeke K, Schoeters I, Gerschel T, Baker S, Dwyer B, Danzeisen R, Adams W, Gaunt R, Van Sprang P, Vangheluwe M, Vandenbroele M, Heijerick D, Verdonck F, Van Hyfte A, Cross H, Sadhra S, Wheatley A, Binetti R, Attias L, Marchini S, Pennelli B, Testai E, Di Prospero Fanghella P, Rubbiani M (2010) The EU copper risk assessment: summary and applications. In Proceedings of Copper 2010. Brussels, Belgium

DiDonato M, Sarkar B (1997) Copper transport and its alterations in Menkes and Wilson diseases. Biochimica et Biophysica Acta 1360:3-16

Dong J, Atwood CS, Anderson VE, Siedlak SL, Smith MA, Perry G, Carey PR (2003) Metal binding and oxidation of amyloid- $\beta$ within isolated senile plaque cores: raman microscopic evidence. Biochemistry 18(42):2768-2773

Donohue J (1997) New ideas after five years of the lead and copper rule: a fresh look at the MCLG for copper. In: Lagos GE, BadillaOhlbaum R (eds) Advances in risk assessment of copper in the environment. Catholic University of Chile, Santiago, Chile, $\mathrm{p}$ 265-272

Drew SC (2017) The case for abandoning therapeutic chelation of copper ions in Alzheimer's disease. Front Neurosci 11:317

European Copper Institute (ECI) (2008) European union risk assessment report: voluntary risk assessmeint of copper, copper II sulphate pentahydrate, copper(I)oxide, copper(II)oxide, dicopper chloride trihydroxide. European Chemicals Agency (ECHA). Brussels, Belgium. http://echa.europa.eu/web/guest/coppervoluntary-risk-assessment-reports

Ellingsen DG, Møller LB, Aaseth J (2015) Copper. In Handbook on the toxicology of metals, 4th edn. Elsvier/Academic Press, Amsterdam, p 765-786

European Food Safety Authority (EFSA) (2015) Scientific opinion on the dietary reference values for copper EFSA panel on dietetic products, nutrition and allergies (NDA). EFSA J 13(10):4253

Fica-Contreras SM, Shuster SO, Durfee ND, Bowe GJK, Henning NJ, Hill SA, Vrla GD, Stillman DR, Suralik KM, Sandwick RK, Choi S (2017) Glycation of Lys-16 and Arg-5 in amyloid- $\beta$ and the presence of $\mathrm{Cu}^{2+}$ play a major role in the oxidative stress mechanism of Alzheimer's disease. JBIC J Biol Inorg Chem 22 (8):1211-1222

Fuentealba IC, Mullins JE, Aburto EM, Lau JC, Cherian GM (2000) Effect of age and sex on liver damage due to excess dietary copper in Fischer 344 rats. Clin Toxicol 38(7):709-717

Gaetke LM, Chow-Johnson HS, Chow CK (2014) Copper: toxicological relevance and mechanisms. Arch Toxicol 88 (11):1929-1938

Gollan JL, Gollan TJ (1998) Wilson disease in 1998: genetic, diagnostic and therapeutic aspects. J Hepatol 28:28-36

Goode CA, Linder MC (1991) Copper and disease in biochemistry of copper. Plenum Press, New York, NY, pp 331-366

Gromadzka G, Chabik G, Mendel T, Wierzchowska A, Rudnicka M, Czlonkowska A (2010) Middle-aged heterozygous carriers of Wilson's disease do not present with significant phenotypic deviations related to copper metabolism. J Genet 89(4):463-467

Haddad DS, Al-Alousi LA, Kantarjian AH (1991) The effect of copper loading on pregnant rats and their offspring. Funct Dev Morphol $1(3): 17-22$
Harris M (2012) Is there a role for micronutrients in the prevention of cognitive declines associated with aging? Vitam Trace Elem 1 (2):1000e105

Harris ZL, Durley AP, Man TK, Gitlin JD (1999) Targeted gene disruption reveals an essential role for ceruloplasmin in cellular iron efflux. PNAS 14(96):10812-10817

Hayashi H, Shinohara T, Goto K, Fujita Y, Murakami Y, Hattori A, Tatsumi Y, Shimizu A, Ichiki T (2012) Liver structures of a patient with idiopathic copper toxicosis. Med Mol Morpho 45 (2): $105-109$

Health Canada (2010) Federal contaminated site risk assessment in Canada, Part II: Health Canada Toxicological Reference Values (TRVs) and Chemical-Specific Factors, Version 2.0. Revised 2012. Health Canada. Ottawa, Canada

Health Canada (2018) Copper in drinking water, guideline technical document for public consultation. Federal-Provincial-Territorial Committee on Drinking Water. Ottawa, Canada

Hébert CD (1993) NTP Technical Report on toxicity studies of cupric sulphate (CAS $\mathrm{N}^{\circ} 7758-99-8$ ) administered in drinking water and feed to F344/N rats and B6C3F1 mice. National Toxicology Program, Toxicity Report Series No. 29, United States Department of Health and Human Services (NIH Publication 93-3352)

Hébert CD, Elwell MR, Travlos GS, Fitz CJ, Bucher JR (1993) Subchronic toxicity of cupric sulfate administered in drinking water and feed to rats and mice. Toxicol Sci 21(4):461-475

Hill GM, Brewer GJ, Juni JE, Prasad AS, Dick RD (1986) Treatment of Wilson's disease with zinc II. Validation of oral 64-copper with copper balance. Am J Med Sci 292(6):344-349

Hunt JR, Gallagher SK, Johnson LK, Lykken GI (1995) High-versus low-meat diets: effects on zinc absorption, iron status, and calcium, copper, iron, magnesium, manganese, nitrogen, phosphorus, and zinc balance in postmenopausal women. Am J Clin Nutr 62(3):621-632

Hunt JR (2003) Bioavailability of iron, zinc, and other trace minerals from vegetarian diets. Am J Clin Nutr 78(3):633S-639S

Intawongse M, Dean JR (2006) In-vitro testing for assessing oral bioaccessibility of trace metals in soil and food samples. Trends Anal Chem 25(9):876-886

IOM (2001) Dietary reference intakes for vitamin A, vitamin K, arsenic, boron, chromium, copper, iodine, iron, manganese, molybdenum, nickel, silicon, vanadium and zinc, ed. Board on Food and Nutrition. US Institute of Medicine. National Academy Press, National Research Council, Washington, DC

IOM (2004) Dietary reference values. Recommended intakes and tolerable upper intake levels. US Institute of Medicine. National Academy Press, National Research Council, Washington, DC

IPCS (1998) Environmental Health Criteria 200. International Programme on Chemical Safety. World Health Organization, Geneva

IRIS (2017) EPA database for the Integrated Risk Information System. US Environmental Protection Agency, Washington, DC. https://www.epa.gov/iris

Ishida S, Andreux P, Poitry-Yamate C, Auwerx J, Hanahan D (2013) Bioavailable copper modulates oxidative phosphorylation and growth of tumors. Proc Natl Acad Sci 110(48):19507-19512

Johnson PE (1988) Effect of various dietary carbohydrates on absorption and excretion of copper in the rat as measured by isotope dilution. J Trace Elem Exp Med 1:143-155

Johnson PW, Lee DY (1988) Copper absorption and excretion measured by two methods in rats fed varying concentrations of dietary copper. J Trace Elem Exp Med 1:129-41

Kaden D. Bush AI, Danzeisen R, Bayer TA, Multhaup G (2011) Disturbed copper bioavailability in Alzheimer's disease. Int $\mathrm{J}$ Alzheimer's Dis 2011:1-5

Kardos J, Heja L, Simon A, Jablonkai I, Kovacs R, Jemnitz K (2018) Copper signalling: causes and consequences. Cell Commun Signal 16:71 
Kessler H, Pajonk FG, Meisser P, Schneider-Axmann T, Hoffmann KH, Supprian T, Herrmann W, Obeid R, Multhaup G, Falkai P, Bayer TA (2006) Cerebrospinal fluid diagnostic markers correlate with lower plasma copper and ceruloplasmin in patients with Alzheimer's disease. J Neural Transm 113(11):1763-9

Kessler H, Bayer TA, Bach D, Schneider-Axmann T, Supprian T, Herrmann W, Haber M, Multhaup G, Falkai P, Pajonk FG (2008) Intake of copper has no effect on cognition in patients with mild Alzheimer's disease: a pilot phase 2 clinical trial. J Neural Transm 115(8):1181

Kimmel CA, Garry MR, DeSesso JM (2014) Relationship between bent long bones, bent scapulae, and wavy ribs: malformations or variations? Birth Defects Res Part B 101(5):379-392

Kitazawa M, Cheng D, LaFerla FM (2009) Chronic copper exposure exacerbates both amyloid and tau pathology and selectively dysregulates cdk5 in a mouse model of AD. J Neurochemistry 108(6): 1550-1560

Kitazawa M, Hsu HW, Medeiros R (2016) Copper exposure perturbs brain inflammatory responses and impairs clearance of amyloidbeta. Toxicological Sci 152(1):194-204

Klevay LM (2010) Copper and cognition. Clin Neurophysiol 121 (12):2177

Krajčovičová-Kudláčková M, Šimončič R, Babinska K, Bederova A, Brtkova A, Magalova T, Grančičová E (1995) Selected vitamins and trace elements in blood of vegetarians. Ann Nutr Metab 39 (6):334-339

Krewski D, Chambers A, Stern BR, Aggett PJ, Plunkett L, Rudenko L (2010a) Development of a copper database for exposure-response analysis. J Toxicol Environ Health, Part A 73(2-3):208-216

Krewski D, Chambers A, Birkett N (2010b) The use of categorical regression in modeling copper exposure-response relationships. J Toxicol Environ Health Part A 73(2-3):187-207

Lee J, Prohaska JR, Thiele DJ (2001) Essential role for mammalian copper transporter $\mathrm{Ctr} 1$ in copper homoestasis and embryonic development. PNAS 98(12):6842-6847

Lee J, Petris MJ, Thiele DJ (2002) Characterization of mouse embryonic cells deficient in the Ctr1 high affinity copper transporter. J Biol Chem 277(43):40253-40259

Lecyk M (1980) Toxicity of CuSO4 in mice embryonic development. Zool Pol 28:101-105

Li D-D, Zhang W, Wang Z-Y, Zhao P (2017) Serum copper, zinc, and iron levels in patients with Alzheimer's disease: a meta-analysis of case-control studies. Front Aging NeuroSci 9:300. 13 pp

Linder MC (2016) Ceruloplasmin and other copper binding components of blood plasma and their functions: an update. Metallomics 8:887-905

Llanos RM, Mercer JF (2002) The molecular basis of copper homeostasis copper-related disorders. DNA Cell Biol 21(4):259-270

Lönnerdalm B (2008) Intestinal regulation of copper homeostasis: a developmental perspective. Am J Clin Nutr $2008 \quad 88$ (suppl):846S-850S

Lovell MA, Robertson JD, Teesdale WJ, Campbell JL, Markesbery WR (1998) Copper, iron and zinc in Alzheimer's disease senile plaques. J Neurological Sci 158(1):47-52

Massie HR, Aiello VR (1984) Excessive intake of copper: Influence on longevity and cadmium accumulation in mice. Mech Ageing Dev 26(2-3):195-203

Maynard CJ, Cappai R, Volitakis I, Cherny RA, White AR, Beyreuther K, Masters CL, Bush AI, Li QX (2002) Overexpression of Alzheimer's disease amyloid- $\beta$ opposes the age-dependent elevations of brain copper and iron. J Biol Chem 277 (47):44670-44676

MDEQ (2013) Cleanup criteria requirements for response activity. Table 4. Toxicological and chemical-physical data. Part 201 generic cleanup criteria and screening levels/Part 213 risk-based screening levels. Michigan Department of Environmental
Quality. https://ars.apps.lara.state.mi.us/AdminCode/DeptBurea uAdminCode? Department $=$ Environment $\% 2 \mathrm{C} \% 20 \mathrm{Great} \% 20 \mathrm{La}$ kes $\% 20$ and $\% 20$ Energy $\&$ Bureau $=$ Remediation $\% 20$ and $\%$ 20Redevelopment\%20Division. https://www.michigan.gov/ documents/deq/deq-rrd-Rules-Table4ToxicologicalChemica 1PhysicalData_447077_7.pdf

MDEQ (2015) Chemical update worksheet: copper. Michigan Department of Environmental Quality. Lansing, Michigan. https://www.michigan.gov/documents/deq/deq-rrd-chemCopperDatasheet_527899_7.pdf

Milton B, Farrell PJ, Birkett N, Krewski D (2017a) Modeling Ushaped exposure-response relationships for agents that demonstrate toxicity due to both excess and deficiency. Risk Anal $37: 265-279$

Milton B, Krewski D, Mattison DR, Karyakina NA, Ramoju S, Shilnikova N, Birkett N, Farrell PJ, McGough D (2017b) Modeling U-shaped dose-response curves for manganese using categorical regression. Neurotoxicology 58:217-225

Ministry of Health, Labour and Welfare (2004) Revision of drinking water quality standards in Japan. Office of Drinking Water Quality Management, Water Supply Division, Health Service Bureau. Tokyo, Japan

Monnot AD, Behl M, Ho S, Zheng W (2011) Regulation of brain copper homeostasis by the brain barrier systems: effects of $\mathrm{Fe}$ overload and Fe-deficiency. Toxicol Appl Pharmacol 256 (3): $249-257$

Monnot AD, Zheng G, Zheng W (2012) Mechanism of copper transport at the blood-cerebrospinal fluid barrier: influence of iron deficiency in an in vitro model. Exp Biol Med 237 (3):327-333

Morris MC, Evans DA, Tangney CC, Bienias JL, Schneider JA, Wilson RS, Scherr PA (2006) Dietary copper and high saturated and trans fat intakes associated with cognitive decline. Arch Neurol 63(8):1085-1088

Müller T, Feichtinger H, Berger H, Müller W (1996) Endemic Tyrolean infantile cirrhosis: an ecogenetic disorder. Lancet 347 (9005):877-880

Musuru J, Robien K, Harnack LJ, Park K, Jacobs Jr. DR (2011) Dietary supplements and mortality in older women: the Iowa women's health study. Arch Intern Med 171(18):1625-1633

Nayak NC, Chitale AR (2013) Indian childhood cirrhosis (ICC) \& ICC-like diseases: the changing scenario of facts versus notions. Indian J Med Res 137(6):1029

NHMRC (2011) Australian drinking water guidelines national water quality management strategy. National Health and Medical Research Council, National Resource Management Ministerial Council, Commonwealth of Australia, Canberra

NRC (2000) Copper in drinking water. National Research Council. National Academies Press. Washington, DC

O'Connor JM, Bonham MP, Turley E, McKeown A, McKelveyMartin VJ, Gilmore WS, Strain JJ (2003) Copper supplementation has no effect on markers of DNA damage and liver function in health adults (FOODCUE Project). Ann Nutr Metab 47:201-206

O’Donohue J, Reid MA, Varghese A, Portmann B, Williams R (1993) Micronodular cirrhosis and acute liver failure due to chronic copper self-intoxication. Eur J Gastroenterol Hepatol 5:561-562

OEHHA (2008) Public health goal for copper in drinking water. California Office of Environmental Health Hazard Assessment, OEHHA

Ohgami RS, Campagna DR, McDonald A, Fleming MD (2006) The Steap proteins are metalloreductases. Blood 108(4):1388-1394

Olivares M, Pizarro F, Speisky H, Lönnerdal B, Uauy R (1998) Copper in infant nutrition: safety of World Health Organization provisional guideline value for copper content of drinking water. J Pediatr Gastroenterol Nutr 26(3):251-257 
Olivares M, Araya M, Pizarro F, Uauy R (2001) Nausea threshold in apparently healthy individuals who drink fluids containing graded concentrations of copper. Regul Toxicol Pharmacol 33 (3):271-275

O’Neill NC, Tanner MS (1989) Uptake of copper from brass vessels by bovine milk and its relevance to Indian childhood cirrhosis. J Pediatr Gastroenterol Nutr 9(2):167-172

Phinney ALB, Drisaldi SD, Schmidt S, Lugowski V, Coronado Y, Liang P, Horne J, Yang J, Sekoulidis J, Coomaraswamy, Chishti MA (2003) In vivo reduction of amyloid- $\beta$ by a mutant copper transporter. PNAS 100(24):14193-14198

Pizarro F, Olivares M, Uauy R, Contreras P, Rebelo A, Gidi V (1999) Acute gastrointestinal effects of graded levels of copper in drinking water. Environ Health Perspect 107(2):117

Pizarro F, Olivares M, Araya M, Gidi V, Uauy R (2001) Gastrointestinal effects associated with soluble and insoluble copper in drinking water. Environ Health Perspect 109(9):949

Pratt WB, Omdahl JL, Sorenson JRJ (1985) Lack of effects of copper gluconate supplementation. Am J Clin Nutr 42:681-682

Reinstein NH, Lonnerdal B, Keen CL, Hurley LS (1984) Zinc-copper interactions in the pregnant rat: fetal outcome and maternal and fetal zinc, copper and iron. J Nutr 114(7):1266-79

Russo AJ, deVito R (2011) Analysis of copper and zinc plasma concentration and the efficacy of zinc therapy in individuals with Asperger's syndrome, pervasive developmental disorder not otherwise specified (PDD-NOS) and autism. Biomark Insights 6:127-133

Schafer S, Pajonk FG, Multhaup G, Bayer TA (2007) Copper and clioquinol treatment in young APP transgenic and wild-type mice: effects on life expectancy, body weight, and metal-ion levels. J Mol Med 85(4):405-13

Scheinberg IH, Sternlieb I (1994) Is non-Indian childhood cirrhosis caused by excess dietary copper? Lancet 344(8928):1002-1004

Schreurs BG (2013) Cholesterol and copper affect learning and memory in the rabbit. Int $\mathrm{J}$ Alzheimer's Dis 2013:1-12. https://www.hindawi.com/journals/ijad/2013/518780/abs/

Singh I, Sagare AP, Coma M, Perlmutter D, Gelein R, Bell RD, Deane RJ, Zhong E, Parisi M, Ciszewski J, Kasper RT (2013) Low levels of copper disrupt brain amyloid- $\beta$ homeostasis by altering its production and clearance. PNAS 110(36):14771-14776

Sjögren M, Blennow K (2005) The link between colesterol and Alzheimer's disease. World J Biol Psychiatry 6(2):85-97

Sparks DL, Schreurs BG (2003) Trace amounts of copper in water induce $\beta$-amyloid plaques and learning deficits in a rabbit model of Alzheimer's disease. Proceedings of the National Academy of Sciences 100(19):11065-11069

Sparks DL (2004) Cholesterol, Copper, and Accumulation of Thioflavine S-Reactive Alzheimer's-Like Amyloid $\beta$ in Rabbit. Brain J Mol Neurosci 24:97-104

Sparks DL, Friedland R, Petanceska S, Schreurs BG, Shi J, Perry G, Smith MA, Sharma A, Derosa S, Ziolkowski C, Stankovic G (2006) Trace copper levels in the drinking water, but not zinc or aluminum influence CNS Alzheimer-like pathology. The. J Nutr, Health Aging 10(4):247

Squitti RD, Lupoi P, Pasqualetti G, Dal Forno F, Vernieri P, Chiovenda L, rossi M, Cortesi E, Cassetta, Rossini RM (2002) Elevation of serum copper levels in Alzheimer's disease. Neurology 59(8):1153-1161

Squitti R, Mendez AJ, Simonelli I, Ricordi C (2017) Diabetes and Alzheimer's disease: can elevated free copper predict the risk of the disease? J Alzheimer's Dis 56:1055-1064

Squitti R, Ghidomi R, Simonelli I, Ivanova ID, Colabufo NA, Zuin M, Benussi L, Binetti G, Cassetta E, Rongioletti M, Siotto M (2018) Copper dyshomeostasis in Wilson disease and Alzheimer's disease as shown by serum and urine copper indicators. J Trace Elem Med Biol 45:181-188
Srikumar TS, Källgård B, Ockerman PA, Akesson B (1992a) The effects of a 2-year switch from a mixed to a lactovegetarian diet on trace element status in hypertensive subjects. Eur J Clin Nutr 46(9):661-669

Srikumar TS, Johansson GK, Ockerman PA, Gustafsson JA, Akesson B (1992b) Trace element status in healthy subjects switching from a mixed to a lactovegetarian diet for $12 \mathrm{mo}$. Am J Clin Nutr 55:1-6

Sriramachari S, Nayak NC (2008) Indian childhood cirrhosis: several dilemmas resolved. Indian J Med Res 128(2):93

Stern BR (2010) Essentiality and toxicity in copper health risk assessment: overview, update and regulatory considerations. J Toxicol Environ Health 73(2-3):114-127

TCEQ (2014) Toxicity factor derivation document for copper, CASRN 7440-50-8. Texas Commission on Environmental Quality (TCEQ), Toxicology Division. Austin, Texas

Tønnesen T, Kleijer WJ, Horn N (1991) Incidence of Menkes disease. Hum Genet 86(4):408-410

Treiber CA, Simons M, Strauss M, Hafner R, Cappai TA, Bayer, Multhaup G (2004) Clioquinol mediates copper uptake and counteracts copper efflux activities of the amyloid precursor protein of Alzheimer's disease. J Biol Chem 279 (50):51958-51964

Turnlund JR, Keyes WR, Anderson HL, Acord LL (1989) Copper absorption and retention in young men at three levels of dietary copper by use of the stable isotope ${ }^{65} \mathrm{Cu}$. Am J Clin Nutr 49:870-878

Turnlund JR, Jacob RA, Keen CL, Strain JJ, Kelley DS, Domek JM, Keyes WR, Ensunsa JL, Lykkesfeldt J, Coulter J (2004) Longterm high copper intake: effects on indexes of copper status, antioxidant status, and immune function in young men. Am J Clin Nutr 79:1037-1344

Turnlund JR, Keyes WR, Kim SK, Domek JM (2005) Long-term high copper intake: effects on copper absorption, retention, and homeostasis in men. Am J Clin Nutr 81(4):822-828

Uauy R, Maass A, Araya M (2008) Estimating risk from copper excess in human populations. Am J Clin Nutr 88(3):867S-871S

US EPA (1988a) Copper chemical assessment summary. US EPA. Washington, DC. https://cfpub.epa.gov/ncea/iris/iris_documents/ documents/subst/0368_summary.pdf

US EPA (1988b) Recommendations for and Documentation of Biological Values for Use in Risk Assessment. US EPA. Washington, DC

US EPA (1993) Reference dose (RfD): description and use in health risk assessments. Background document 1A. US Environmental Protection Agency. US EPA. Washington, DC

US EPA (1997) Exposure factors handbook. US Environmental Protection Agency, Office of Research and Development, Washington, DC

US EPA (2000) CatReg software user manual. US Environmental Protection Agency, Office of Research and Development, National Center for Environmental Assessment; EPA/600/R-98/ 052, Research Triangle Park, NC, https://www.epa.gov/bmds/ca treg

US EPA (2007) Framework for metals risk assessment. EPA 120/R07/001. Office of the Science Advisor, US EPA. Washington, DC

US EPA (2017) Regional screening levels (RSLs)—generic tables November 2017. US EPA, Washington, DC

USDA (1996) 1994-1996 continuing survey of food intakes by individuals and 1994-1996 diet and health knowledge survey. Food surveys research group, Beltsville Human Nutrition Research Center, Maryland

Van den Berg GJ, Yu S, Lemmens AG, Beynen. AC (1994) Ascorbic acid feeding of rats reduces copper absorption, causing impaired copper status and depressed biliary copper excretion. Biol Trace Elem Res 41(1-2):47-58 
Van den Berghe PVE, Klomp LWJ (2009) New developments in the regulation of intestinal copper absorption. Nutr Rev 67(11):658-672

Wapnir RA (1998) Copper absorption and bioavailability. Am J Clin Nutr 67(5):1054S-1060S

Winge DR, Mehra RK (1990) Host defenses against copper toxicity. Int Rev Exp Pathol 31:47-83

Weiss KC, Linder MC (1985) Copper transport in rats involving a new plasma protein. Am J Physiol-Endocrinol Metab 249(1):E77-E88

White AR, Reyes R, Mercer JF, Camakaris J, Zheng H, Bush AI, Multhaup G, Beyreuther K, Masters CL, Cappai R (1999) Copper levels are increased in the cerelbral cortex and liver of APP and APLP2 knockout mice. Brain Res 842(2):439-444

WHO (1996) Trace elements in human nutrition and health. World Health Organization. Geneva, Switzerland

WHO (2002) Principles and methods for the assessment of risks from trace elements. World Health Organization. Geneva, Switzerland. http://www.inchem.org/documents/ehc/ehc/ehc228.htm

WHO (2004) Copper in drinking-water. Background document for development of World Health Organization guidelines for drinking-water quality. WHO. Geneva, Switzerland
WHO (2018) A global overview of national regulations and standards for drinking-water quality. WHO, Geneva, Switzerland

Wyllie J (1957) Copper poisoning at a cocktail party. Am J Public Health 47(617): 1

Xu GG, Salen S, Shefer GS, Tint BT, Kren LB, Nguyen CJ, Steer TS, Chen L, Salen, Greenblatt D (1997) Increased bile acid pool inhibits cholesterol $7 \alpha$-hydroxylase in cholesterol-fed rabbits. Gastroentrol 113:1958-1965

Xu J, Church SJ, Patassini S, Begley P, Waldvogel HJ, Curtis MA, Faull RL, Unwin RD, Cooper GJ (2017) Evidence for widespread, severe brain copper deficiency in Alzheimer's dementia. Metallomics 9(8):1106-1109

Zheng W, Monnot AD (2012) Regulation of brain iron and copper homeostasis by brain barrier systems: implication in neurodegenerative diseases. Pharmacol Therapeutics 133 (2): 177-188

Zietz BP, Dieter HH, Lakomek M, Schneider H, Kessler-Gaedtke B, Dunkelberg H (2003) Epidemiological investigation on chronic copper toxicity to children exposed via public drinking water supply. Sci Tot Environ 302(1-3):127-144 